\title{
Full scale measurements of train underbody flows and track forces
}

D. Soper, C. Baker, A. Jackson, University of Birmingham, Birmingham, United Kingdom

D. R. Milne, L. Le Pen, G. Watson, W. Powrie, University of Southampton, Southampton, United Kingdom

\begin{abstract}
This paper presents the results of full scale measurements of the underbody flow characteristics and track behaviour beneath a high speed train on a line in the south of England. Simultaneous measurements were made of the flow velocities and pressures beneath the train, sleeper displacements and ballast accelerations. The results showed that, while the mechanical measurements of displacement and acceleration were essentially deterministic and varied little from one train passage to another, the aerodynamic measurements were highly variable with substantial run-to-run variation. Vertical ballast accelerations with peaks greater than the acceleration due to gravity were measured for short durations. Velocity and turbulence intensity profiles were derived, from which aerodynamic shear forces at the ballast surface were estimated. Assessment of the magnitudes of the different forces acting on the ballast showed that the mechanical forces associated with track displacement and the aerodynamic forces were of similar order of magnitude on well performing track. For poorly maintained track with higher accelerations, the effects of track vibration on the initiation of ballast motion are likley to be much more significant.
\end{abstract}

Keywords - train underbody flow; aerodynamic loads on track; boundary layers; ballast

\section{Publication information}

This paper was accepted for publication on 31 July 2017, Available online 8 August 2017.

The citation for the article in Harvard style is:

Soper, D., Baker, C., Jackson, A., Milne, D. R., Le Pen, L., Watson, G. \& Powrie, W. 2017. Full scale measurements of train underbody flows and track forces. Journal of Wind Engineering and Industrial Aerodynamics, 169, 251-264.

https://doi.org/10.1016/j.jweia.2017.07.023 


\section{Introduction}

Ballast projection or flight is the phenomenon by which ballast grains may become airborne during the passage of a high-speed train. Airborne ballast can cause extensive damage to the underbody of a train, and to the railhead if trapped between a wheel and the rail. Further evidence of ballast flight may include damaged wheel sets, broken glass in stations and damaged trackside acoustic screens. It has been conjectured that the phenomenon is caused by strong aerodynamic flows between the train underbody and the track, coupled with mechanical excitation during a train passage (Quinn et al, 2010).

Ballast flight seems to manifest itself in different ways in different countries. During ICE3 tests in France and Belgium in normal weather conditions in 2003 and 2004, large quantities of quite large ballast grains became airborne and caused extensive pitting of train under bodies (Kaltenbach 2008) and similar incidents have been reported in Italy and Spain. Elsewhere in Europe (including the UK) and in the Far East, lumps of ice falling from trains can displace ballast, causing train and track damage (Shinojima 1984). In the UK, the problem appears mainly to result from smaller ballast grains being lifted onto the track, where they are crushed by either the train that caused the ballast to lift or by a following train, leading to pitting of the wheel and rail and the need for more regular maintenance (Quinn et al 2010).

The phenomenon of ballast flight has prompted a significant amount of research around the world, particularly within Europe through the Aerodynamics in the Open Air (AOA) (Kaltenbach 2008) and AeroTRAIN projects (Sima et al 2011). A number of investigators have measured aerodynamic flows beneath trains at full scale (Kwon and Park 2006, Deeg et al 2008, Quinn et al 2010, Premoli et al 2015 ) and at model scale (Kwon and Park 2006, Kaltenbach et al 2008, Ido et al 2008, 2009, 2013, Jonnson et al 2012, 2013,). CFD calculations have also been carried out (eg. Sima et al 2008, Garcia et al 2011).

Full-scale tests have been carried out in a number of countries (Korea, Japan, France, Germany, Italy, Spain, UK), with different track types (slab track and different sleeper / ballast configurations). Wind tunnel tests have been carried out over a range of scales, with and without simulation of the track bed itself. Tests using a model train propelled by a car have been reported by Ido et al $(2008,2009,2013)$. In general, CFD calculations have used standard RANS methods, and some authors have carried out comparisons with equivalent experimental results. The overall trends from these measurements and calculations are clear, showing a highly sheared and turbulent flow near the ground and an indication that bogie cavities can increase both the magnitudes of the flow and its unsteadiness. The type of the sleeper and the height of the ballast above or below the sleeper top have significant effects on the apparent aerodynamic roughness of the track.

Ballast flight itself has been studied analytically (Sanz-Andres and Navarro-Medina 2010, Quinn et al 2010, Jing et al 2012) and experimentally at both model scale using large scale wind tunnel rigs (Kwon and Park 2006, Kaltenbach et al 2008), and at full scale using instrumented ballast (Quinn et al 2010, Premoli et al 2015) and train borne microphones to assess impacts (Premoli et al 2015). It has come to be generally accepted that the primary parameter in assessing ballast flight is a measure of the horizontal velocity beneath the train (i.e. drag / shear forces on the ballast); hence much effort has been put into 
determining these and correlating them with ballast movement. Although a number of authors have mentioned the possibility of track vibrations playing a role in ballast flight, this has only been studied in two investigations - Quinn et al 2010, with acknowledged shortcomings in the instrumentation, and Premoli et al 2015. The evidence here is somewhat contradictory, with early authors such as Luo et al 1996 predicting track and ballast accelerations of the order of one $g$ or more Conversely, the more recent measurements of Premoli et al 2015 suggest much lower ballast accelerations of the order of $0.2 \mathrm{~g}$, leading them to conclude that track vibrations are not a relevant issue. This divergence of view will be addressed later.

A number of authors present models and methods for assessing the risk and mitigating the effects of ballast flight. With regard to risk assessment, Saussine et al 2009, 2013 developed an outline methodology involving the "stress" on the bed caused by the passage of the train (based on the velocity beneath the train), and the "strength" of the bed (defined by the mean and standard deviation of the number of ballast particles moved at a particular "stress"). The probability of ballast movement can then be calculated from a convolution of the two probability distributions. The "stress" and the "strain" are not as conventionally defined, the former being an observed function of the train type and the latter of the track characteristics.

Both track and train based methods of mitigation have been proposed. The most frequently advocated track based methods are the use of slab track (i.e. the complete removal of ballast), lowering the ballast to well below sleeper height, adjusting the sleeper shape and ballast gluing. In terms of train modifications, proposals have been made for shielding bogies and reducing the high mean velocities and turbulence levels in their vicinity, and for generally smoothing the undersurface of the train to reduce near-track velocities (Kaltenbach, 2008).

Finally, work is underway within CEN to develop a testing methodology that can be used in train homologation. The current proposal, based on the oucomes of the AeroTRAIN project, and contained in CEN (2013) as an informative annex), is for tests to be carried out to measure the flow velocities beneath a train on a section of track where a smooth surface has been created by covering the ballast (Weise et al 2013). It is acknowledged that this method lacks realism, but it does allow a comparison to be made between different train types. The proposed methodology is still however complex and resource intensive, and agreement on its implementation has not yet been reached.

The work reported in this paper formed part of a project whose objectives were

- to investigate the interaction between track / ballast vibration effects and aerodynamic effects on the initiation of ballast flight; hence to address the uncertainties that have arisen from earlier work;

- to investigate the possibilities of using scale moving model tests and an advanced unsteady CFD methodology to predict the flow field beneath trains, hence to assess such methods as possible future options for the homologation of new trains, that would be less restrictive and resource intensive than field monitoring.

This paper presents the results of on-track monitoring in which concurrent measurements were made of the aerodynamic velocities and pressures, track displacements and ballast 
accelerations. These measurements have contributed to our understanding of the interaction between the aerodynamic and geotechnical aspects of ballast flight, and provide a detailed set of data for comparison with model test and CFD calculations. Other aspects of the project will be presented elsewhere. Section 2 of this paper describes the field monitoring carried out, and the analysis techniques used. The main results are presented in section 3. Section 4 discusses these results and analyses some aspects of the data in greater detail. In particular it investigates the conditions where ballast flight might be initiated. Concluding comments are given in section 5 .

\section{Field measurement methodology}

\subsection{Test site}

Field monitoring was carried out on a high speed railway line in the UK which has been the subject of previous aerodynamic and geotechnical investigations (Quinn et al 2010). Figure 1 shows a schematic plan of the site, with the locations of the instrumentation indicated. The site is situated on the down line of a relatively straight section of twin track. A schematic of the equipment set up is shown in Figure 2. The aerodynamic measurement equipment was mounted on a gauge bar across the track, and geotechnical measurements made at a number of locations ahead of and behind the gauge bar. The co-ordinate system used in this paper has its origin at the instrument position on the gauge bar at the centre of the track (COT), at the height of the top of the rail (TOR). $x$ is measured along the track, $y$ across the track, and $z$ vertically upwards. Trains pass at or near to the maximum line speed of $83 \mathrm{~m} / \mathrm{s}(300 \mathrm{~km} / \mathrm{h})$. The track is ballasted with twin block sleepers supporting type E60 rails. A small cutting lined with low density shrubbery begins just before the test site, but this is not thought to have had any influence on the results. The main study site investigated was chosen as representative of a well performing section of track, with track movements well within the generally accepted range $(<2 \mathrm{~mm})$. Further along the same section of track, a trackbed fault was present. Sleeper movements at the location of the fault were measured using the techniques described in this paper; and the results will be used below to illustrate the behaviour of less well performing track and how it may contribute to ballast flight.

\subsection{The monitored train}

A number of different train types operate on the high speed railway on which the investigations took place. This paper will focus on data from just one of these types - the 20 vehicle, 394m long Class 373 Eurostar. The train comprises two identical 10 vehicle sets coupled together. The first vehicle of each set is the driving car; the second and tenth are semi-articulated, with seven articulated vehicles between them. Thus there are three different bogie arrangements between adjoining vehicles. Between the driving vehicle and the first semi-articulated vehicle, and where the two vehicle sets are coupled together, there are pairs of unconnected bogies ( 4 axles in total). The centre to centre bogie spacing between the two vehicle sets $(6.29 \mathrm{~m})$ is a little greater than between the driving and semi articulated vehicles $(6.275 \mathrm{~m})$. Adjoining ends of articulated vehicles are supported on a single, two-axle bogie. 
Gauge bar :

Vertical geophone $\bigcirc$

Instrumented ballast :•

Ultrasonic anemometer $\bigoplus$
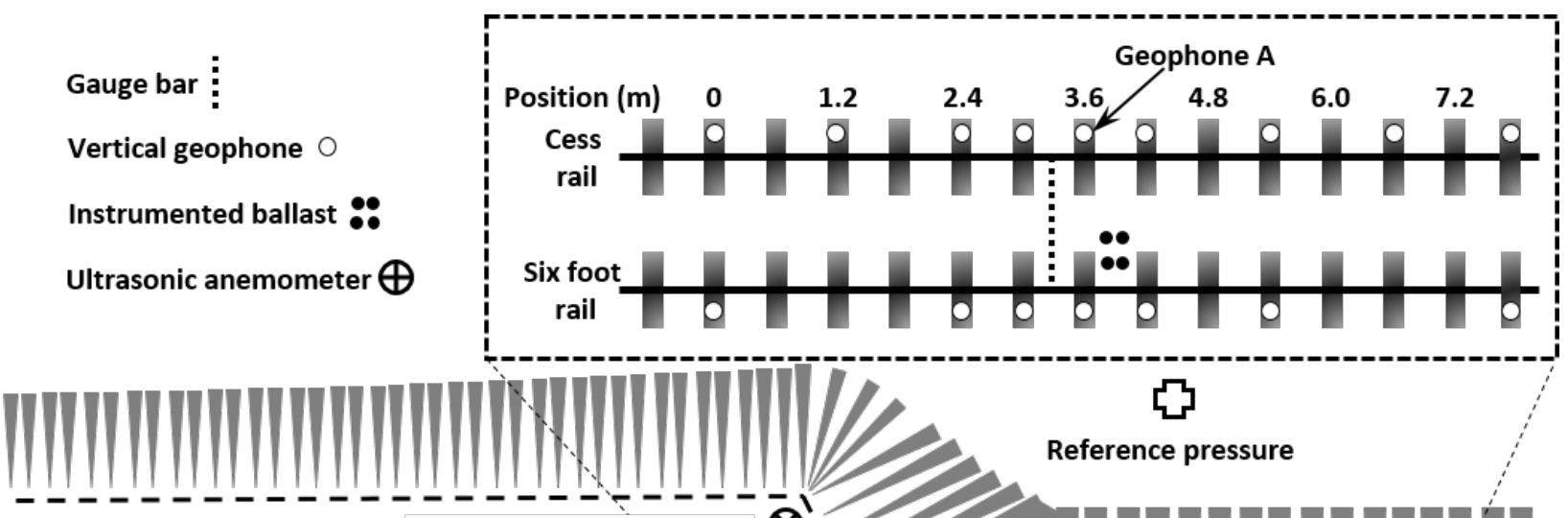

Reference anemometer

Hard standing
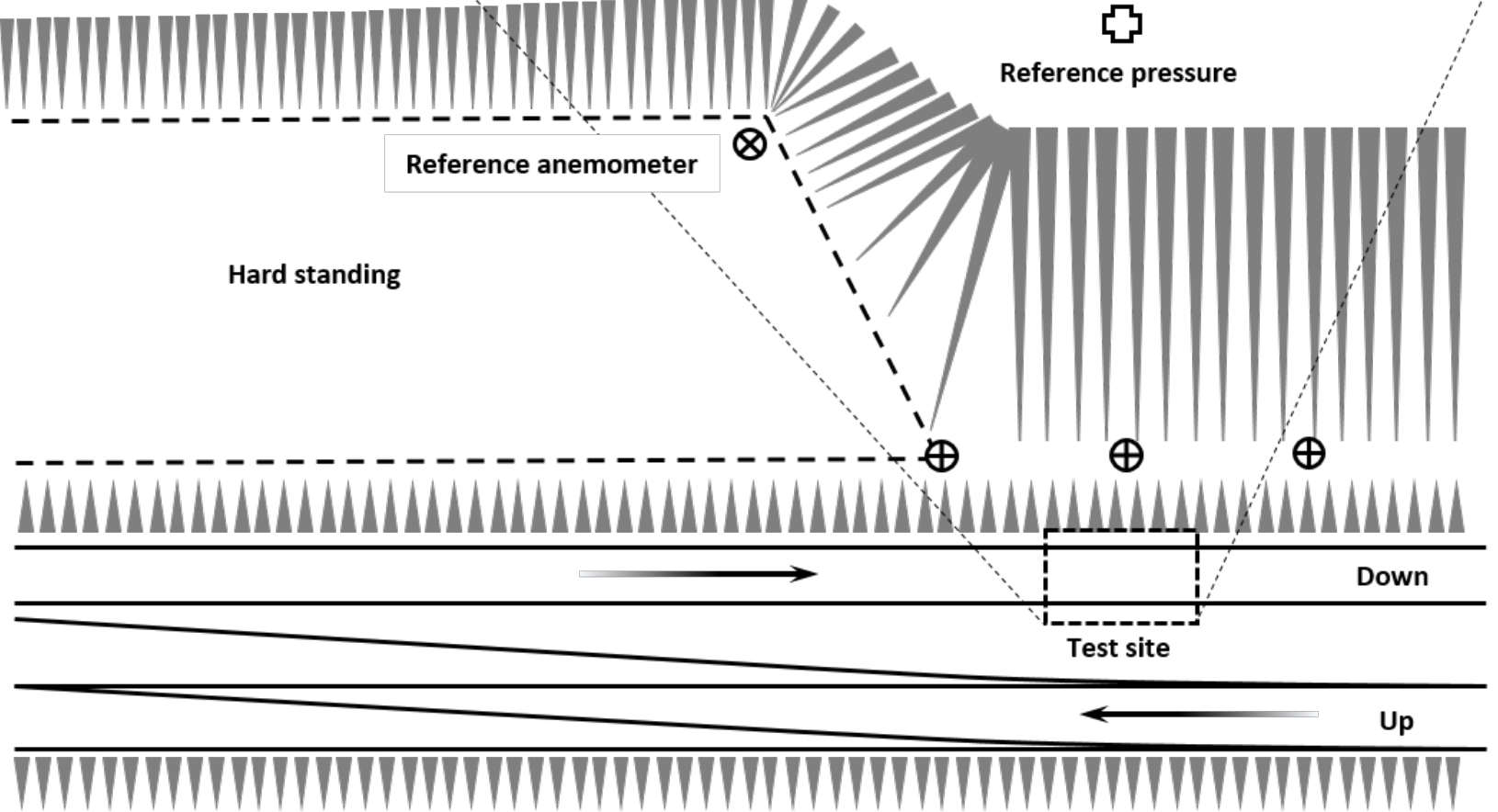

Figure 1 Experimental site

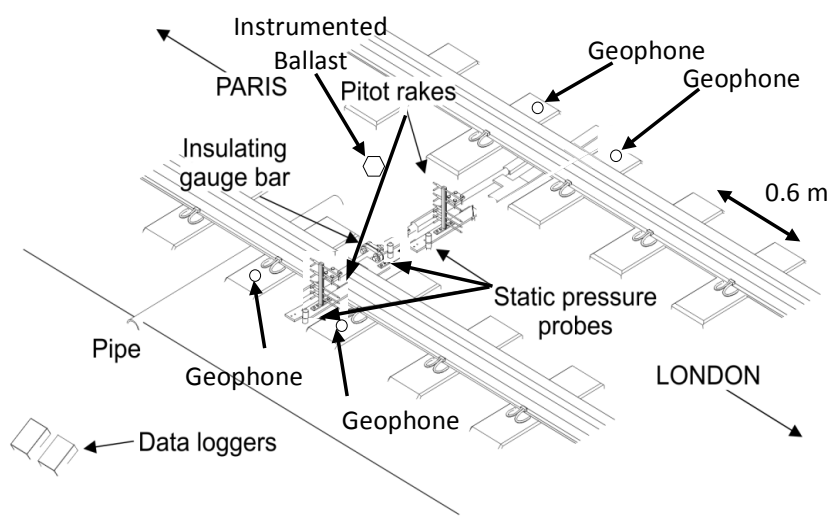

Ballast shoulder

Figure 2. A schematic of the instrumentation setup (sonic anemometers not shown for clarity) 


\subsection{Track deflection and ballast acceleration measurements}

Measurements of track and ballast velocities and accelerations were carried out using geophones supplied by Ion Sensor Nederland LF-24 geophones mounted on selected sleeper ends and accelerometers embedded into ballast grains placed on the ballast surface. 16 vertical geophone sensors were used ( 9 at the cess end and 7 at the six foot end), centred on the gauge bar used for the aerodynamic measurements (see below). Geophones are small velocity transducers that may be fixed to a sleeper top and connected by cable to a data logger to record sleeper movement velocities as trains pass. The measured voltages are converted to velocities by applying an appropriate calibration in the frequency domain and filtering. Velocities may then be converted to displacements and accelerations by integrating or differentiating as necessary (e.g. Le Pen, et al., 2014). The use of geophones to measure sleeper movements as trains pass has become established practice as interpretation techniques have advanced (e.g. Bowness et al., 2007, Le Pen et al., 2016). Several sleepers on either side of the gauge bar were instrumented at both the cess and $6 \mathrm{ft}$ ends thereafter, alternate sleepers were instrumented with some sleepers only being instrumented at the cess end (Figure 1). These geophones are shown in the photograph of Figure 3a. Geophone output was recorded at $500 \mathrm{~Hz}$ using a Campbell 9000 data logger (Campbell Scientific, 2014), triggered automatically by an approaching train with 4 seconds of data buffered and recorded ahead of the train and 16 seconds of data recorded after the first axle triggered the sensor. Most trains travelling at line speed will pass a location in less than 10 seconds.

Recently, micro electrical mechanical systems (MEMs) type accelerometers, as used in consumer electronics, have been used for trackside measurements (Milne et al., 2016b \& Lamas-Lopez, et al., 2014). MEMs are small and low cost. Sensors of this type (AXIVITY AX3), complete with a long life battery, data aquistion system and internal memory have been fitted within specially hollowed out ballast grains to obtain measurements of the accelerations within the ballast bed without cables (Milne et al., 2016a). The four instrumented ballast grains were pressed into the ballast surface so that their tops were level with the surrounding crib ballast. Figure 3(b), taken during the night-time installation works, shows some of the instrumented ballast grains located on the crib ballast between the rails. Each instrumented grain passed a $50 \mathrm{~mm}$ sieve but not a $35 \mathrm{~mm}$ sieve, and thus may be taken to have a nominal dimension of $40 \mathrm{~mm}$. Ballast acceleration was sampled continuously at $400 \mathrm{~Hz}$. Individual train passes were identified and extracted from the data. 


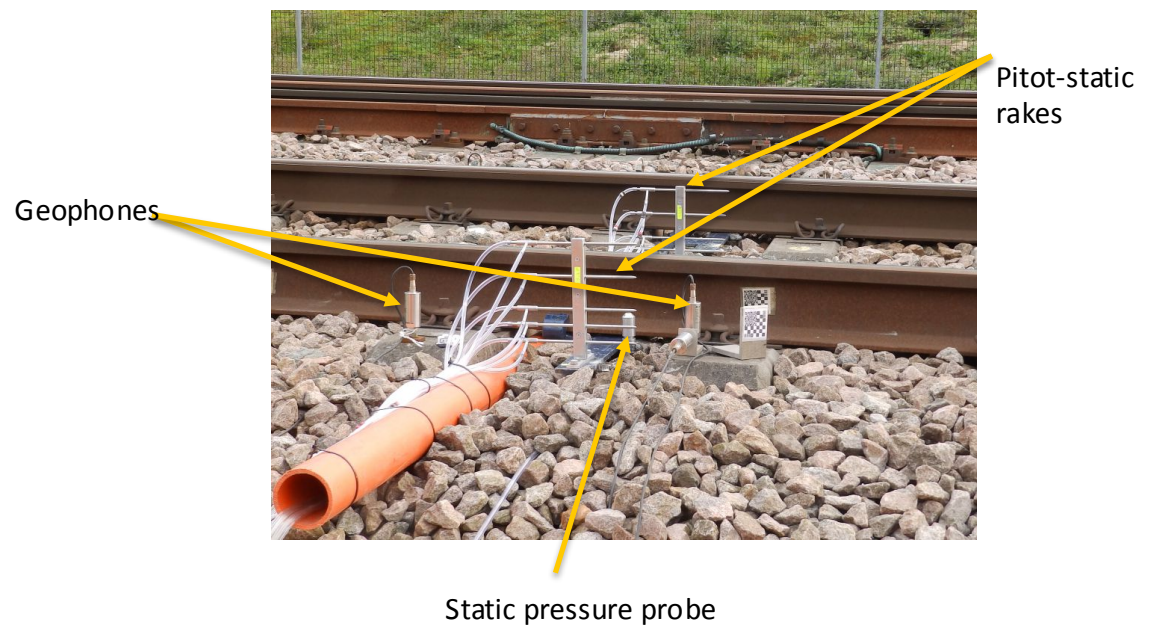

a) Instrumentation set up

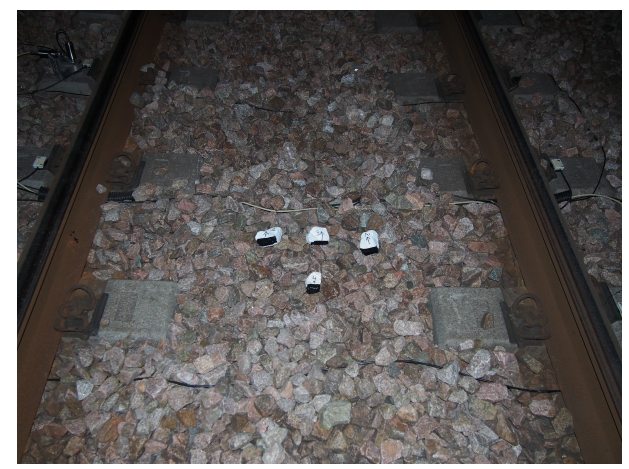

b) Instrumented ballast stones

Figure 3. The experimental equipment

\subsection{Aerodynamic investigations}

Aerodynamic measurements of slipstream velocities and static pressures on the trackbed were made beneath the train and in the bogie region using a number of instrument types, as shown in Figures 2 and 3a. Two rakes of pitot-static tubes were positioned on the trackbed to measure the total horizontal velocity at a range of heights above the ballast bed. Each rake has five measuring heights, as shown in Table 1. Rakes were positioned at the centre of track and $1.085 \mathrm{~m}$ from the centre of track, outside the four-foot (the distance between the running rails) in the cess. Pitot tubes were used for this investigation because they were robust (and thus suited to the extreme environment beneath trains), and earlier experiments using multi-hole probes suggested that the flow was within the yaw angle range for which pitots are known to be insensitive to yaw (Quinn et al 2010). 
The pneumatic tubes for the Pitot probe total and static tappings were individually tuned before installation by fitting restrictors (in a similar fashion to that described by Irwin et al 1979). This ensured that both the total and static tappings showed no attenuation of the signal for frequencies below approximately $30 \mathrm{~Hz}$. The tubing for the static pressure probes was not tuned in any way, but the distortion caused by the tubing was corrected using the method described by Irwin et al 1979. In addition to the pitot-static rakes, a series of static pressure probes was positioned level with the ballast to record the static pressure on the trackbed at a range of lateral positions (Table 1). The probes were designed by Hoxey et al [Hoxey et al., 1979] for measuring the static pressure on the surface of a building without the need for a pressure tap. They have been shown to record static pressures beneath a train accurately by Quinn et al (2010). The instrumentation in the four-foot was mounted on an adapted railway gauge bar via flat plates and jubilee clips, enabling it to be positioned securely at ballast level.

All pressure measuring instrumentation was connected, via pneumatic tubing through a pipe beneath the running rail, to custom-built data acquisition units positioned on the ballast shoulder. This prevented any interference from track circuit currents. The data loggers recorded pressure signals digitally at a sampling frequency of $256 \mathrm{~Hz}$, with data being saved to a built-in SSD card. The instrumentation was powered by deep cycle $12 \mathrm{~V}$ rechargable batteries, which were changed/rotated throughout the monitoring period. Pressure transducers (First Sensor SQ276-43EB) were mounted directly to the logger PCB board, and pneumatic tubes connected the measuring ports to adapters built into the side of the data logger casing. All reference pressure ports were connected to a manifold, which was connected to a long pneumatic tube fed away from the track to the top of the small cutting, away from any influence from passing trains. A static pressure probe was connected to the end of the reference pressure tubing to protect the tube from rainfall and insects.

Three ultrasonic anemometers (Gill Instruments types R3-50 and R3-100) were positioned in the cess to measure the development of slipstream velocities in the train bogie region at three positions from centre of track, as shown in Table 1 . The anemometers were connected to small AntiLog RS232 data loggers and powered by $12 \mathrm{~V}$ batteries. A reference $10 \mathrm{~Hz}$ anemometer was set up at a distance of $14.85 \mathrm{~m}$ from the centre of track and at a height of $3 \mathrm{~m}$, to record ambient wind conditions. Finally, additional static pressure probes were positioned in the cess (train side) at either end of the test site, to measure the train speed based on the initial change in pressure relating to the train nose. The probes were set up in front of and behind the gauge bar $52.69 \mathrm{~m}$ apart (not shown in Figure 1). Previous studies, using a railway-specific speed gun, have shown that this method enables train speed to be determined accurately. Atmospheric pressure and temperature were measured using a GBP3300 Digital Barometer and an Oregon Scientific BAR208HGA respectively. 
Table 1. Aerodynamic instrument position details

\begin{tabular}{|c|c|c|c|c|c|c|c|c|}
\hline \multirow[b]{3}{*}{$y$} & \multirow{2}{*}{\multicolumn{2}{|c|}{$\begin{array}{c}\text { Pitot-static rakes } \\
0 \mathrm{~m}\end{array}$}} & \multicolumn{3}{|c|}{ Static pressure } & \multicolumn{3}{|c|}{ Ultrasonic anemometer } \\
\hline & & & \multicolumn{3}{|c|}{$0 \mathrm{~m}$} & $-9.3 m$ & $-0.5 \mathrm{~m}$ & $9.3 \mathrm{~m}$ \\
\hline & $0 \mathrm{~m}$ & $1.085 \mathrm{~m}$ & $0.16 \mathrm{~m}$ & $0.64 \mathrm{~m}$ & $0.82 \mathrm{~m}$ & $3.6 \mathrm{~m}$ & $4.0 \mathrm{~m}$ & $3.5 \mathrm{~m}$ \\
\hline \multirow{5}{*}{$\begin{array}{l}z(0=\text { rail } \\
\text { top level) }\end{array}$} & \multicolumn{2}{|c|}{$\begin{array}{c}-0.18 \text { m (Ballast } \\
\text { surface) }\end{array}$} & \multicolumn{3}{|c|}{$-0.18 m$} & \multicolumn{3}{|c|}{$0.2 \mathrm{~m}$} \\
\hline & \multicolumn{2}{|c|}{$-0.14 m$} & & & & & & \\
\hline & \multicolumn{2}{|c|}{$-0.09 \mathrm{~m}$} & & & & & & \\
\hline & \multicolumn{2}{|c|}{$-0.02 \mathrm{~m}$} & & & & & & \\
\hline & \multicolumn{2}{|c|}{$0.05 \mathrm{~m}$} & & & & & & \\
\hline
\end{tabular}

Table 2 Experimental details

\begin{tabular}{|c|c|c|c|}
\hline Run number & Date and time & Train speed $(\mathrm{m} / \mathrm{s})$ & Windspeed $(\mathrm{m} / \mathrm{s})$ \\
\hline 1 & 20160511_0607 & 63.6 & 0.18 \\
\hline 2 & 20160511_0713 & 80.6 & 0.50 \\
\hline 3 & 20160511_0721 & 78.9 & 0.54 \\
\hline 4 & 20160511_0823 & 75.6 & 0.46 \\
\hline 5 & 20160511_0923 & 80.2 & 0.64 \\
\hline 6 & 20160511_0944 & 82.4 & 0.84 \\
\hline 7 & 20160511_1042 & 80.7 & 1.12 \\
\hline 8 & 20160511_1325 & 80.9 & 1.46 \\
\hline 9 & 20160511_1423 & 74.4 & 1.08 \\
\hline 10 & 20160511_1442 & 81.3 & 1.38 \\
\hline 11 & 20160511_1523 & 78.2 & 1.61 \\
\hline 12 & 20160511_1752 & 73.5 & 0.49 \\
\hline 13 & 20160511_1921 & 75.9 & 0.30 \\
\hline 14 & 20160511_1954 & 81.3 & 0.41 \\
\hline
\end{tabular}




\subsection{Field monitoring conditions and runs}

In total, 14 passages of Class 373 Eurostar trains were recorded and the train and wind speeds are given in Table 2 . The table also shows the reference wind speeds measured during the tests. These are below the $2 \mathrm{~m} / \mathrm{s}$ values the specified for slipstream and pressure measurements in the CEN standard (CEN 2013).

\subsection{Analysis methodologies}

The time/displacement behaviour of each of the instrumented sleepers at the study site has been found to be very repeatable between passages of similar types of train. However, because of the turbulent nature of the flow field, the air flow around and under trains is inherently very unsteady, and aerodynamic measurements made during different passages of the same train type can vary widely. It will be seen that the instrumented ballast grain measurements of acceleration are also largely repeatable; acceleration is closely associated with but somewhat more variable than the track displacement, perhaps reflecting the influence of aerodynamic variability. There is therefore, a mixture of deterministic and stochastic effects; hence different approaches have been adopted to processing and analysing the data for the various measurement techniques used.

In general the measured sleeper movement and ballast grain accelerations are very similar from run to run. Thus the outputs from individual runs are plotted and analysed, and where appropriate considered together with the aerodynamic measurements from individual runs.

For the aerodynamic measurements, the highly turbulent nature of the flow field beneath the train necessitates an appropriate statistical method of analysis. In this paper, we use two methods;

- a detailed analysis of the data from individual train passes;

- ensemble averaging, in which the time histories for all the runs were aligned and averaged to obtain time histories of the mean and standard deviations of the pressure and velocity fields.

Train speeds varied frbetween runs (Table 2). To account for this, in previous studies, raw data have been resampled with respect to a reference train speed. This method is applicable when the train length is relatively short, as the train speed can be considered constant. However, for longer trains, applying a nominal resampling methodology can create a difference in the position for the train tail from run to run, as the train speed can vary slightly during the run. Thus a new method of aligning the raw data was devised in which the time series were initially realigned with respect to the train nose positive pressure peak and the time histories stretched and aligned such that the correlation between results from all the different runs was maximised. Once aligned, data were normalised with respect to individual train speeds and ensemble averages created such that 
$U(T)=\frac{u(T)}{V_{\text {train }}}$

$C_{p}(T)=\frac{p(T)-p_{0}}{0.5 \rho V_{\text {train }}{ }^{2}}$

where $u(T)$ is the measured horizontal velocity in the $x$ direction, $p(T)$ is the measured pressure and $p_{0}$ is the undisturbed atmospheric pressure. $V_{\text {train }}$ is the train speed and $\rho$ is the density of air. $C_{p}(T)$ is of course the standard definition for pressure coefficient. $T$ is a dimensionless time given by

$T=\frac{t V_{\text {train }}}{L}$

where $t$ is the time measured from the passage of the nose of the train, and $L$ is the train length. Thus $T=0$ corresponds to the start of the train and $T=1$ corresponds to the tail of the train.

Table 2 shows that 14 runs were available. This is less than would have been ideal, but was all that could practically be measured in the experimental programme. However experiments at both full scale and model scale indicate that ensemble averages calculated from 10 and 20 run samples were similar and the data obtained in these experiments could be used with confidence.

\section{Results}

Figure 4 shows the range of sleeper movements recorded at each geophone location for the 14 trains considered (Table 2). These are the peak to trough movements obtained by applying the appropriate frequency domain calibration, then filtering and integrating the geophone native velocity measurements. Figure 4 is representative of typical ballasted railway track performance even on well maintained high speed lines, in that nearby sleepers and opposite ends of the same sleeper have significantly different ranges of movement. At this site, the range of sleeper movement is approximately $0.3 \mathrm{~mm}$ to $1.5 \mathrm{~mm}$. Although different sleepers have different movements, individual sleepers perform substantially similarly for trains of the same type passing at the same speed as indicated by the small range of the bars in Figure 4. This is further demonstrated by considering the $1^{\text {st }}$ and 99 th percentiles of the track and ballast accelerations for each run (which reflects the peak values of these parameters), and the variability of this percentile from run-to-run (Figures $5 a$ and b). It can be seen that the percentile values are highly dependent upon the filtering frequency. Comparison of Figure 4 and 5 a also indicates that accelerations are approximately in proportion to the displacement ranges measured for the respective sleeper locations - as is expected for well performing track. 


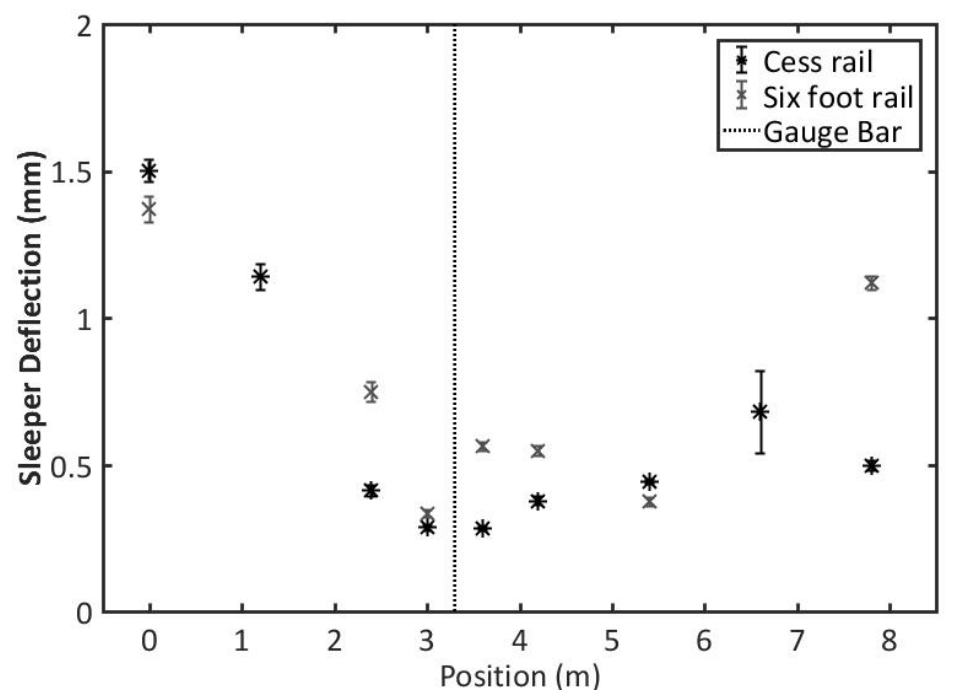

Figure 4. Sleeper movement ranges for the trains shown in Table 2.

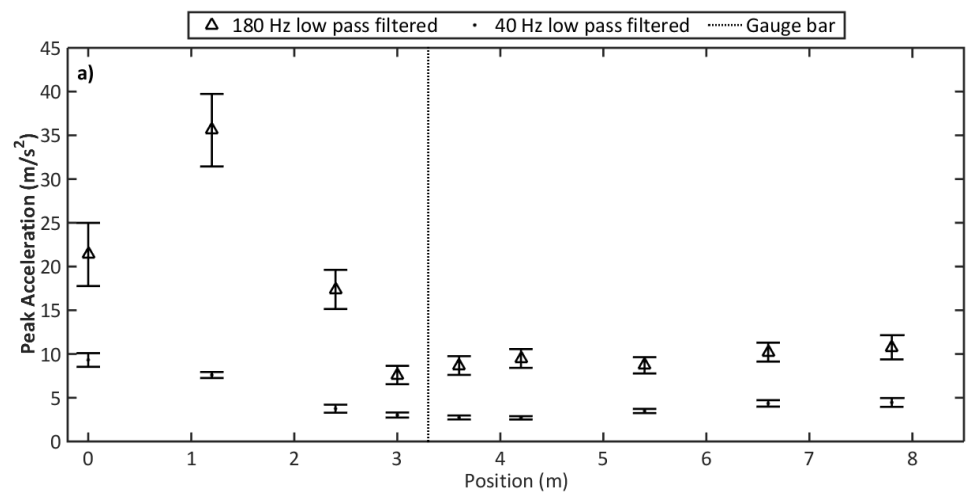

(a)

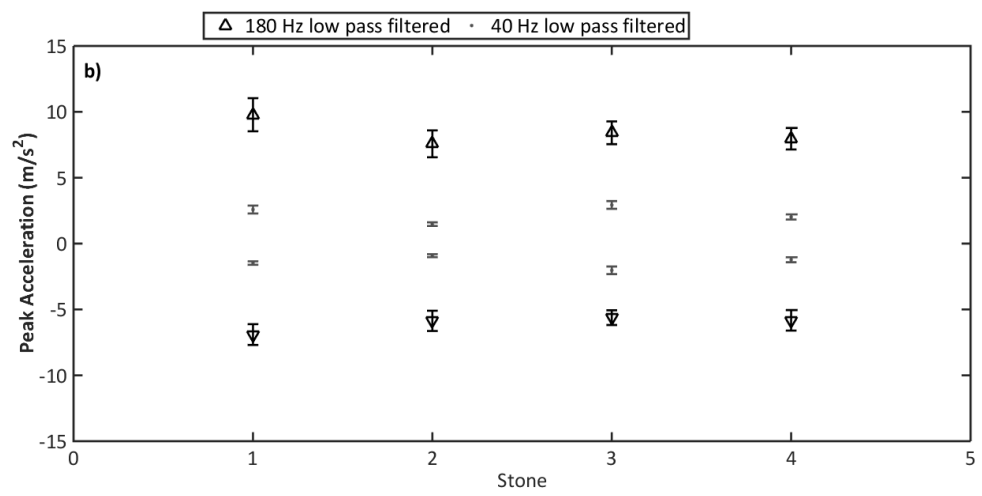

(b)

Figure 5. Mean 1st and 99th percentile (a) cess end positive sleeper acceleration (b) ballast grain acceleration for different filtering cutoffs for the trains shown in Table 2. 
Data from geophone $A$ at the location shown in Figures 1 and 2 and from one of the instrumented ballast grains is presented in more detail for Run 7 in Figure 6. Geophone $A$ is on the cess sleeper end located $0.3 \mathrm{~m}$ behind the gauge bar. The instrumented ballast grain was located approximately $0.6 \mathrm{~m}$ after the gauge bar on top of the next crib (Figure $3 \mathrm{~b}$ ). The track displacement, velocity and acceleration at geophone A for run 7 are shown in Figure 6, filtered with a $180 \mathrm{~Hz}$ cut off. Figure 6a shows that after the passage of the first driving car, the 7 successive articulated passenger cars of the first trainset give rise to a repeating pattern of sleeper movement, which is interrupted at the end of the first train set (i.e. the middle of the overall train) and then repeated until the passage of the final driving car. Figure $6 \mathrm{~b}$ shows the velocity and Figure $6 \mathrm{c}$ the acceleration. The peak velocity is just greater than $20 \mathrm{~mm} / \mathrm{s}$ and peak accelerations are of the order of one $g$. These values are much higher than those observed by Premoli et al (2015). This may be because Premoli's results were low pass filtered at $40 \mathrm{~Hz}$, while the results were presented here were low pass filtered at $180 \mathrm{~Hz}$. Figure 7 shows the results of Figure 6 filtered at $40 \mathrm{~Hz}$. In this case, the accelerations can be seen to be similar to those of Premoli et al (2015).

The sleeper and ballast movements at the study site are representative of well performing track where ballast flight is unlikely. However, there are locations where sleeper movements can be greater. Figure 8 shows data for a sleeper with a trackbed fault that has led to voiding (gapping) between the trackbed ballast and the sleeper. The gap between the sleeper and the ballast meant that as trains passed the sleeper impacted the trackbed with a greater displacement range and much increased velocities and accelerations. At this location a MEMs accelerometer was used to record the sleeper movement because the high velocities meant that the geophones normally used would have been off scale. The characteristics of the particular sensor used (type ADXL326) are described in Milne et al., (2016b). This sensor has an in built $50 \mathrm{~Hz}$ filter so higher frequency data were not available. To be consistent with Figure 7 , data were low pass filtered with a $40 \mathrm{~Hz}$ cut off, so the peak velocities and accelerations of Figure 8 are representative of the average peak persisting over $1 / 40$ of a second. The sleeper for which data are shown in Figure 8 has a peak velocity approaching $0.6 \mathrm{~m} / \mathrm{s}$. The accelerations also significantly exceed gravity (approaching $10 \mathrm{~g}$ ), albeit for only short durations.

Figure 9 compares the track displacement at geophone $A$ with the ballast acceleration, the static pressure at the ballast surface and the air velocity just above the ballast surface. The timescale on Figure 9 has been replaced with units of train passage ( $0=$ train start, $1=$ train end) to facilitate comparison. Note that these measurement positions were not quite coincident, with the sleeper measurements being $30 \mathrm{~cm}$ ahead of and the ballast acceleration $60 \mathrm{~cm}$ behind the pressure and velocity measurements at the gauge bar. For a train length of $390 \mathrm{~m}$, these correspond to dimensionless times of 0.0008 and 0.0016 respectively, both of which are close to the sampling time for the velocity and pressure measurements and barely discernible in Figure 9. These small differences will not be considered further. 

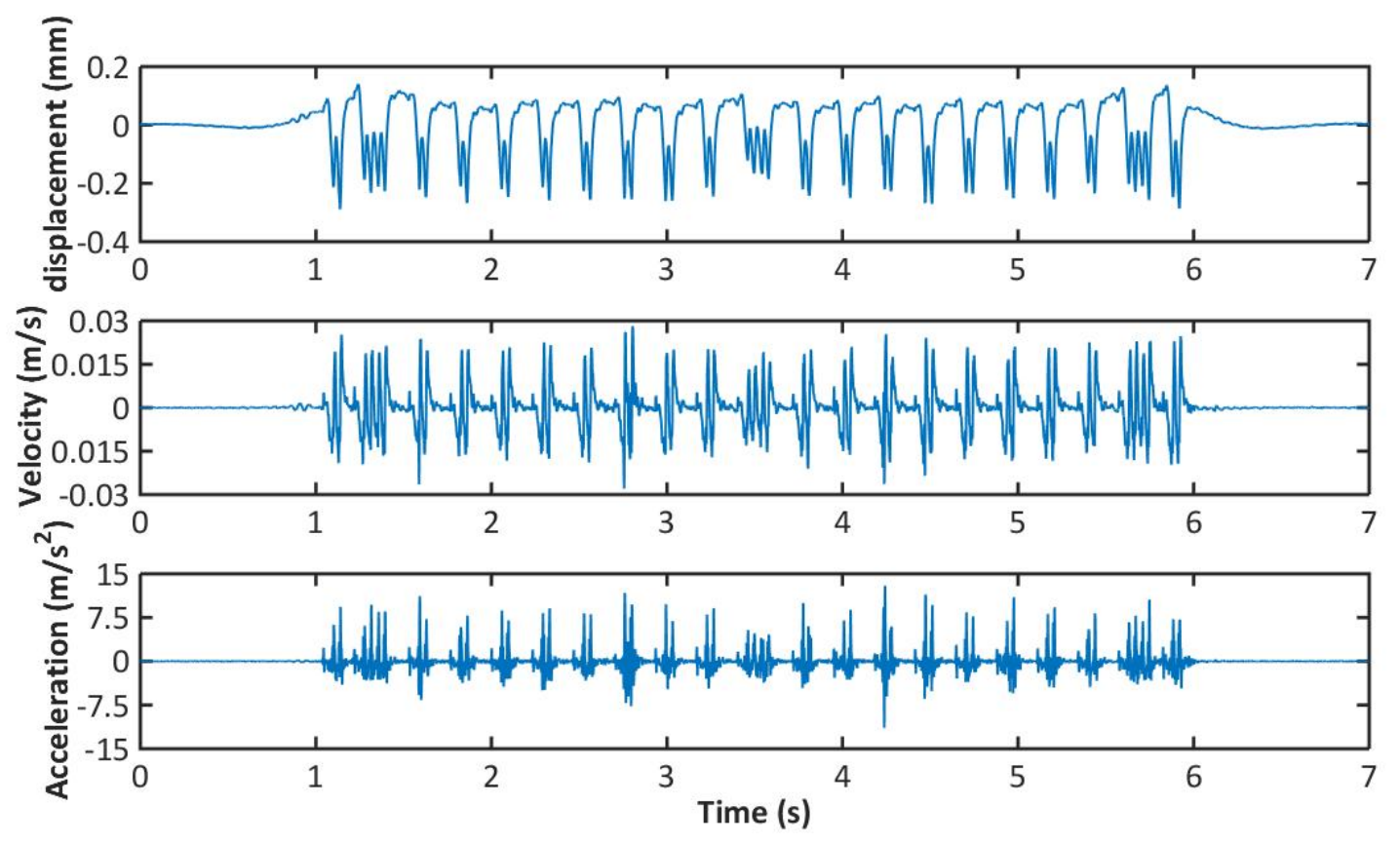

Figure 6. Geophone A Run 7 filtered at $180 \mathrm{~Hz}$ (a) deflection (b) velocity (c) acceleration.

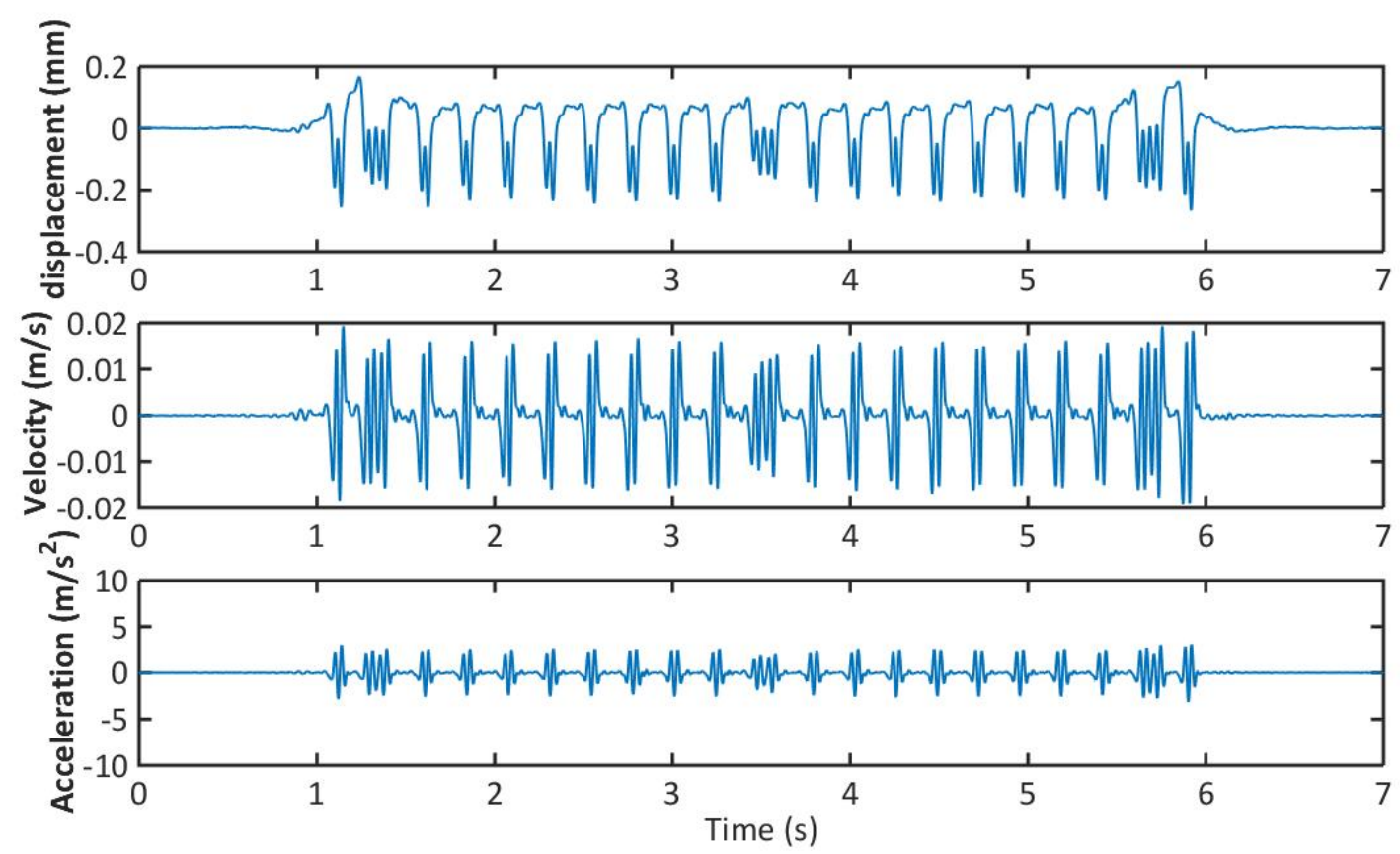

Figure 7. Geophone A Run 7 filtered at $40 \mathrm{~Hz}$ (a) deflection (b) velocity (c) acceleration. 

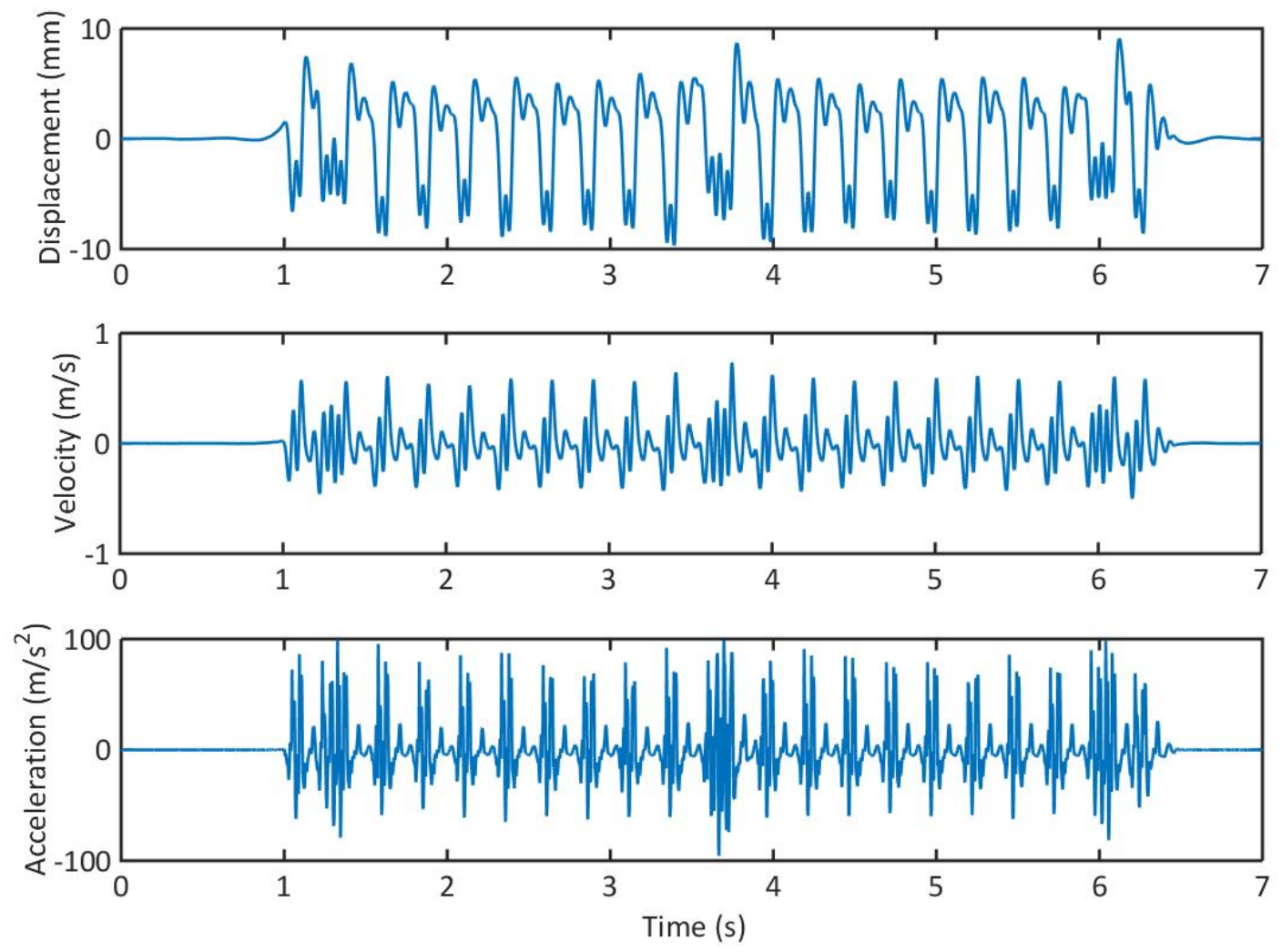

Figure 8. MEMs data from a voided sleeper filtered with a high cut off at $40 \mathrm{~Hz}$ (a) deflection (b) velocity (c) acceleration.

The sleeper displacement data (Figure 9a) show the positions of the bogies and the different bogie types and spacings along the train. Displacements are similar in form for all bogies, with those for the three double bogies being smaller than for the articulated bogies. The bursts of significant ballast acceleration (Figure $9 \mathrm{~b}$ ) are clearly associated with the passage of bogies, and show oscillations initiated by bogie passage continuing after the bogie has passed. Maximum instantaneous upward accelerations occasionally exceed gravitational acceleration. The pressure coefficients (Figure 9c) show the expected large positive and negative peaks around the train nose and tail, as observed in many experiments at the sides and roofs of trains. The effect of bogie passage is also clear, with a negative pressure after the passage of a bogie rising to become slightly positive before the passage of the next bogie. As expected, the air velocity measurements (Figure 9d) show significant fluctuations, as a result of large scale turbulent eddies beneath the train. A number of peaks can be discerned, although their significance is not clear from the study of just one train passage. This will be considered further below. 


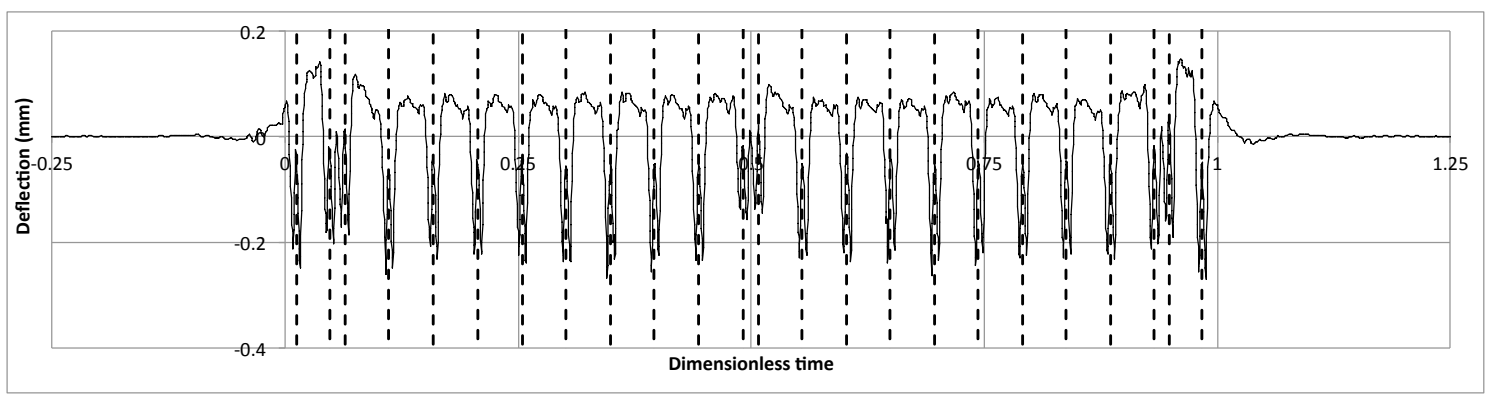

a) Sleeper displacement filtered at $180 \mathrm{~Hz}$ (geophone $3, x=0.3 \mathrm{~m}$ )

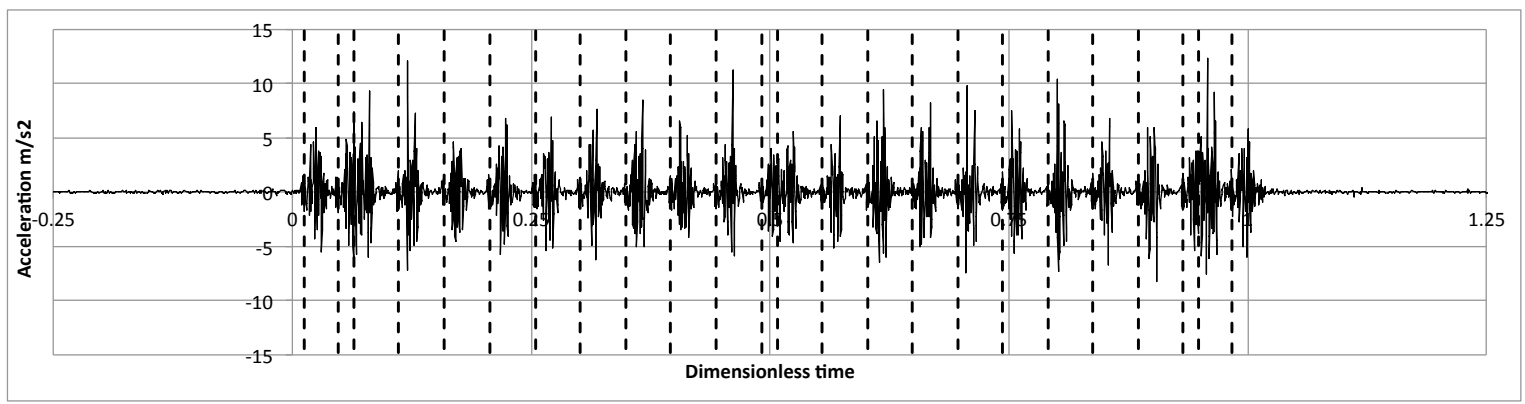

b) Ballast acceleration filtered at $180 \mathrm{~Hz}(x=0.6 \mathrm{~m})$

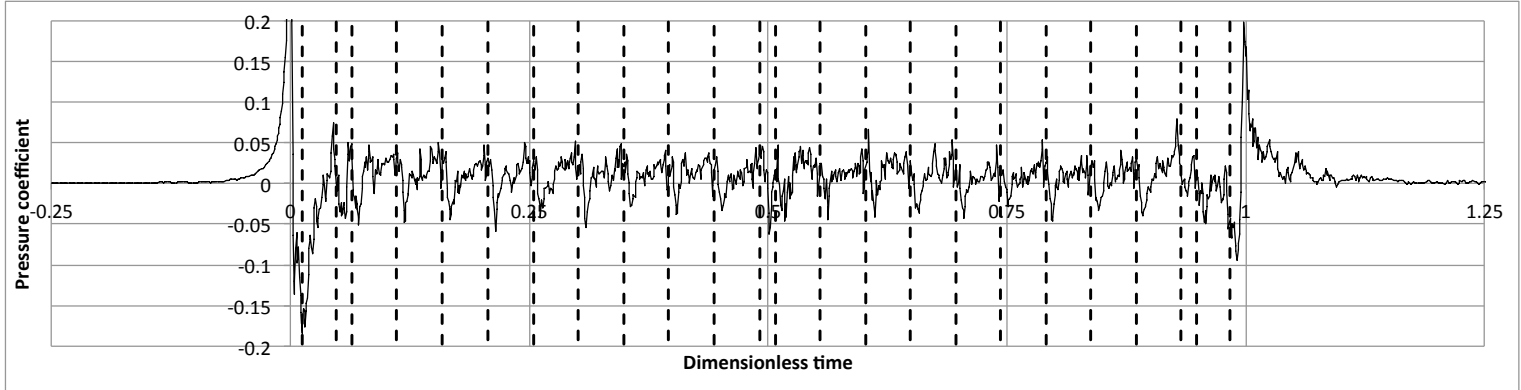

c) Surface pressure at $x=0 \mathrm{~m}, y=0.16 \mathrm{~m}, z=-0.18 \mathrm{~m}$ filtered at $256 \mathrm{~Hz}$

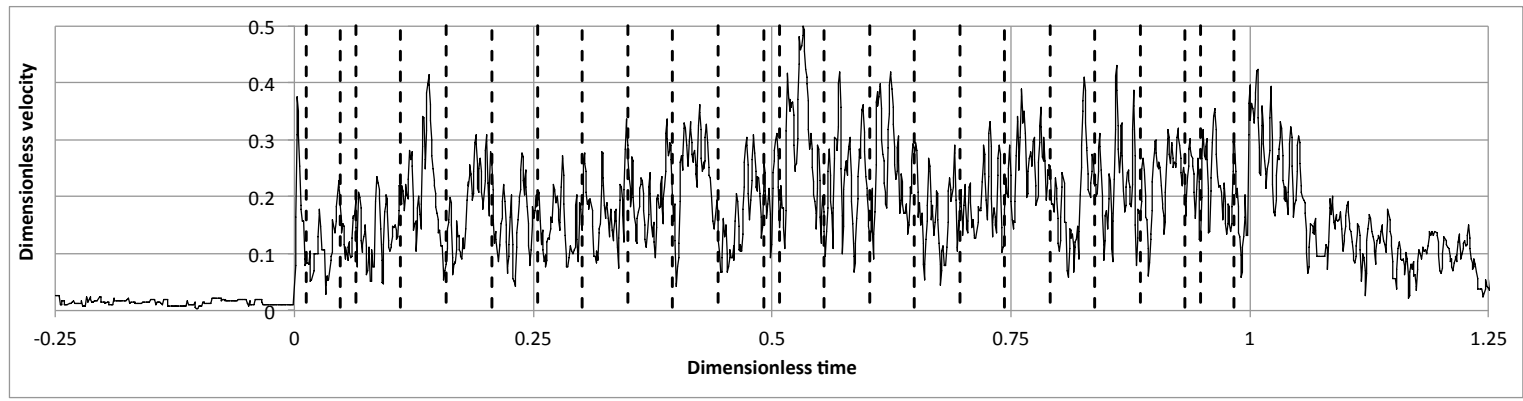

d) Flow velocity at $x=0 \mathrm{~m}, y=0 \mathrm{~m}, z=-0.18 \mathrm{~m}$ filtered at $256 \mathrm{~Hz}$

Figure 9. Time histories for run 7 (dotted lines indicate bogie passage) 
Comparing Figure $9 b$ with Figure $6 c$ the accelerations of the sleeper at the location of geophone $A$ and the accelerations of a ballast grain on top of the nearby crib ballast are comparable and occasionally exceed $1 \mathrm{~g}$ for at least $1 / 180$ of a second. The good match between sleeper and crib ballast movement is perhaps to be expected on this well performing track, where the sleeper appears to be in good contact with the ballast.

Figure 10 compares the pressure and velocity time histories for run 7 with the ensemble averages for these parameters across all train passages. The pressure coefficient / time history is close to that for the ensemble, with variations occurring due to high frequency pressure fluctuations in the turbulent flow field. However, the velocity varies significantly about the ensemble mean; with the latter showing that, in average terms, there are significant velocity peaks around the central bogie pair and at the end of the train. The other peaks in the data for run 7 are not reflected in the ensemble.

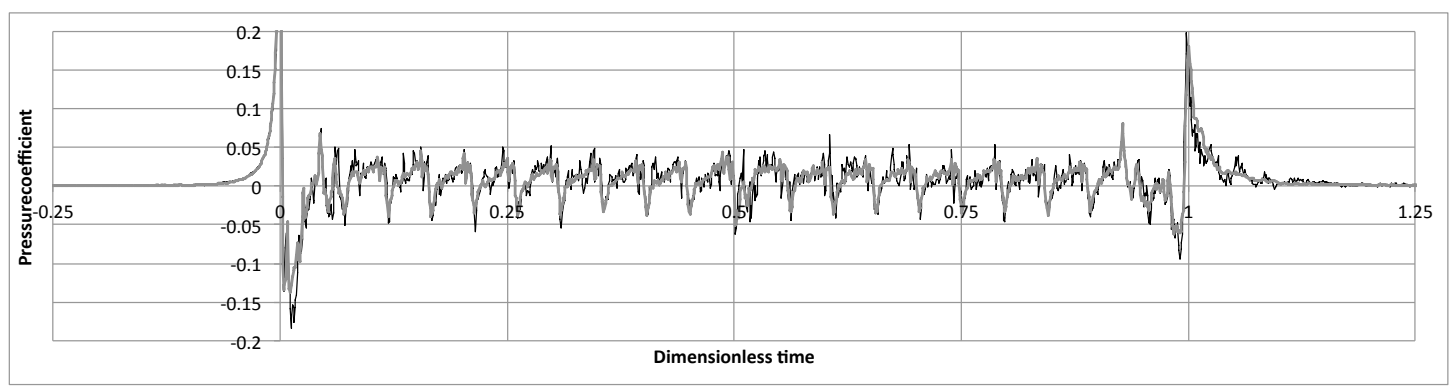

a) Pressure coefficient for run 7 (black) and all run ensemble (grey)

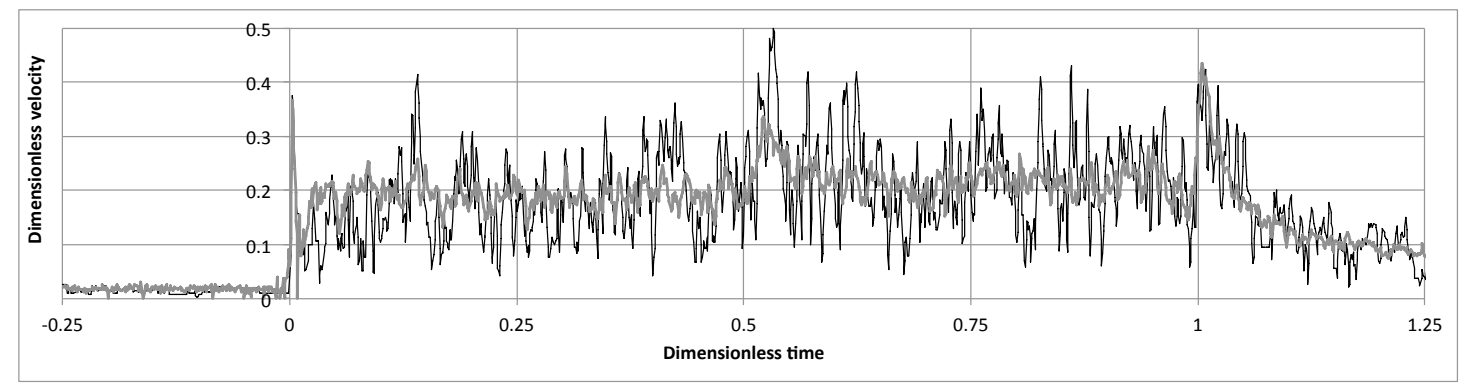

b) Flow velocity for run 7 (black) and all run ensemble (grey)

Figure 10. Relationship between run 7 and ensembles

The mean and standard deviations of the velocity and pressure ensembles are shown in Figure 11. The variation in flow velocity with height is clear, and there are noticeable peaks close to the centre and at the end of the train in all traces. The standard deviation of the velocity ensemble is about 0.07 for all heights. The pressure coefficient reduces a little from the centre to the outside of the track, with standard deviations being small throughout. 

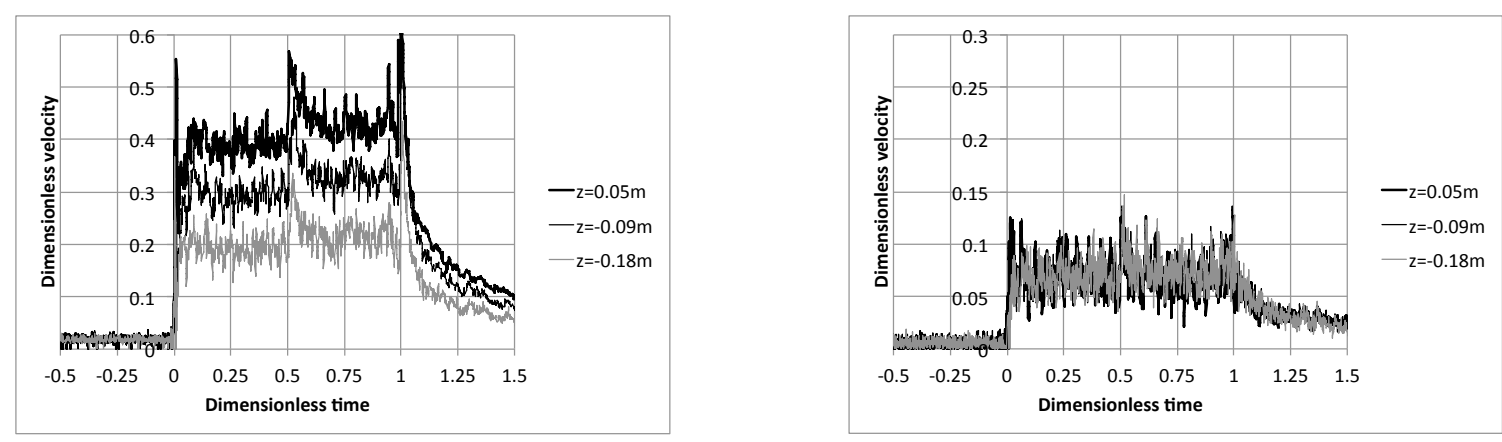

a) Mean and standard deviation of velocities at various heights on centre line $y=0 \mathrm{~m}$
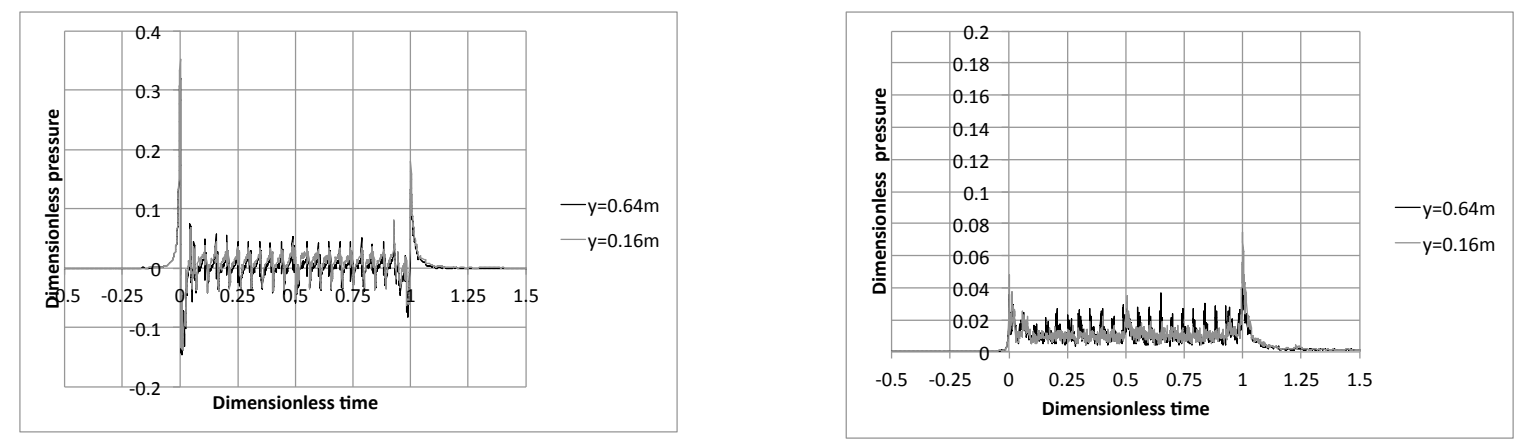

b) Mean and standard deviation of pressure coefficients on ballast surface $z=-0.18 \mathrm{~m}$

Figure 11. Ensemble averages and standard deviations of velocities and pressures

Figure 12 compares the velocity ensembles at the track centre and away from the track - just outside the four foot (from a second pitot rake) and at positions close to the TSI slipstream measuring position (CEN 2013,TSI 2014) at greater distances from the four foot (from sonic anemometers). It can be seen that, beneath the train, the velocities show the expected increase with height with the values at $z=0.05 \mathrm{~m}$ above the top of rail approaching half the train speed. The maximum values are as would be expected around the connection between units. Outside the train, the velocities measured by the anemometers are of a completely different form, with a gradually rising velocity along the train, and a peak in the near wake. Such traces are typical for streamlined trains.

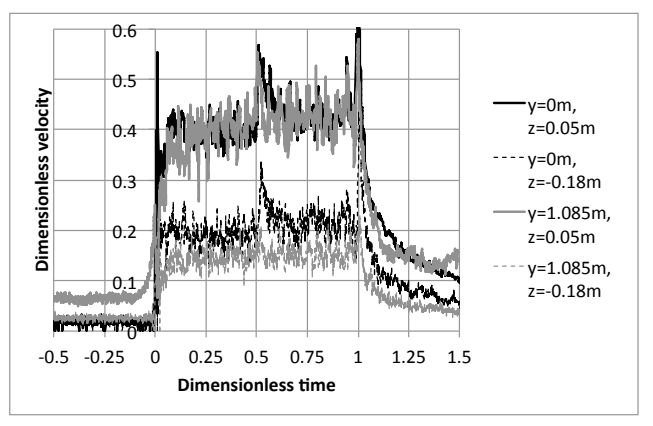

a) Velocity measured using pitot rakes

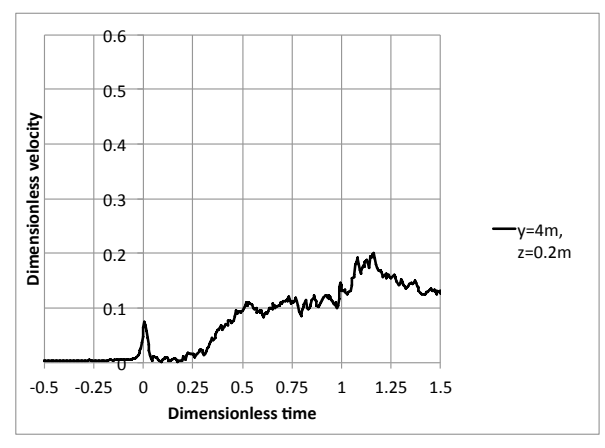

b) Velocity measured using sonic anemometer

Figure 12. Velocity measurements away from the track centre line 


\section{Analysis and discussion}

\subsection{Velocity profile analysis}

Figure $13(\mathrm{a})$ and (b) shows the velocity and turbulence intensity profiles below the train at a number of sections along the track. These represent an average of the ensembles along the lengths of the train indicated. The turbulence intensities are simply the ensemble standard deviations of the velocities over the ensemble mean, this approach being appropriate for the fixed ground based frame of reference. The velocity profiles are of the expected form (Figure 13a). The highest velocities occur just after the junction between the two halves of the train. The turbulence intensity profiles (Figure 13b) are also of the expected form, with high values near the ground, and show little variation along the train.

The velocities in the boundary layer near the track would be expected to show a logarithmic variation with height, from which both the surface roughness length and the shear velocity may be estimated. Deeg et al (2008) show that there is considerable uncertainty in such a curve fit, in terms of the position of the virtual origin and how many measurement points to consider; this is also the case here. After some trial and error, a logarithmic equation of the following form was fitted to the bottom three data points.

$u=\frac{u_{\tau}}{k} \ln \left(\frac{z-h}{z_{0}}\right)$

where $u_{\tau}$ is the friction velocity $(=\sqrt{\tau / \rho}), \tau$ is the surface shear stress, $k$ is the von Karman constant $(=0.41), h$ is the ground plane displacement, $\rho$ is the density of air and $z_{0}$ is the surface roughness length. Taking the bottom three points with a value of $h$ of $-0.19 \mathrm{~m}$, which coincides roughly with the actual surface of the sleeper, was found to give the lowest residuals in the curve fit. The fitted values of $z_{0}$ are shown in Figure 13c, and are of the order of $7 \mathrm{~mm}$ along the length of the train. The values of $\frac{u_{\tau}}{V_{\text {train }}}$ along the train were of the order of 0.11 to 0.13 . These values are also shown in Figure $13 \mathrm{~d}$ in the form of a friction coefficient

$C_{\tau}=2\left(\frac{u_{\tau}}{V_{\text {train }}}\right)^{2}$

This is approximately constant at around 0.03 along the length of the train, which is reasonable for a rough wall boundary layer, although there is a peak just beyond the central bogie. In general these results agree with those of Deeg et al (2008) for ballasted track. They measured values of $\frac{u_{\tau}}{v_{\text {train }}}$ of around 0.12 to 0.16 , and values of $z_{0}$ (calculated from their values of sand grain roughness) of around 2 to $3 \mathrm{~mm}$. They also remarked on the difficulty and arbitrariness of the curve fitting procedure.

At this point the analysis of Garcia et al (2011) is worth mentioning. They developed an analytical model of a turbulent Couette flow and found that to fit experimental data from earlier full scale tests on ballasted track they required sand grain roughnesses for the bed of around $30 \mathrm{~mm}$, with an equivalent value of $z_{0}$ of $1 \mathrm{~mm}$. For the current experiments, the best fit to their analysis (not shown here) was for a sand grain roughness of $60 \mathrm{~mm}$, giving a value of $z_{0}$ of $2 \mathrm{~mm}$, significantly less than the measurements, and a value of $\frac{u_{\tau}}{V_{\text {train }}}$ of 0.031 , again significantly less than measured here. The same discrepancies were observed by Garcia et al 
(2011) when fitting their model to the work of Deeg et al (2008). These discrepancies can perhaps be attributed to the underlying assumptions that they make of constant shear stress across the under train gap, and of two dimensionality. There seems to be no physical reason why the former assumption should be valid in the highly turbulent flow beneath a train. With regard to the latter, the work of Quinn et al (2010) for the same track and train as used in these experiments, indicates strong inward flow towards the centre of the track at the nose and tail regions, with generally outward flow along the rest of the train, and the experiments of Deeg et al (2008) show a significant lateral variation of air speed across the track.

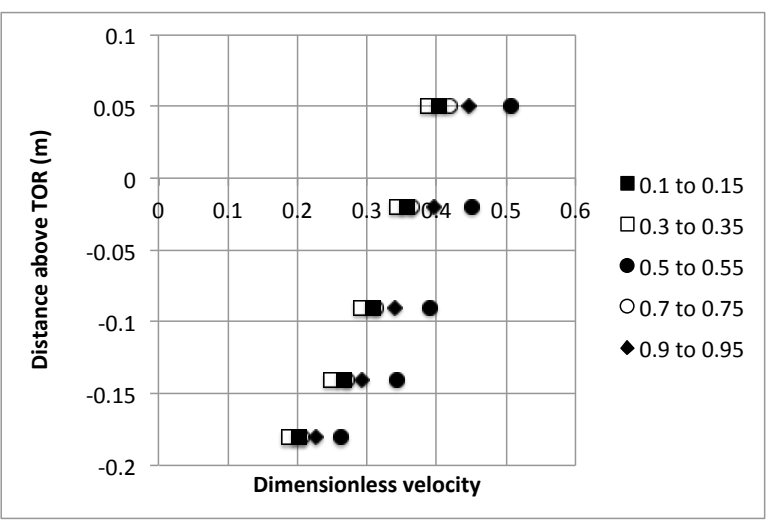

a) Velocity profiles (1.0 = train speed) for different positions along the train

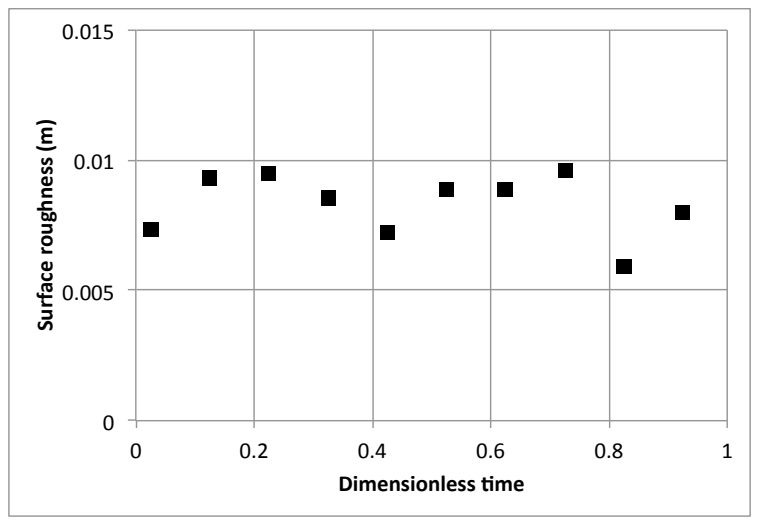

c) Surface roughness development $z_{0}$

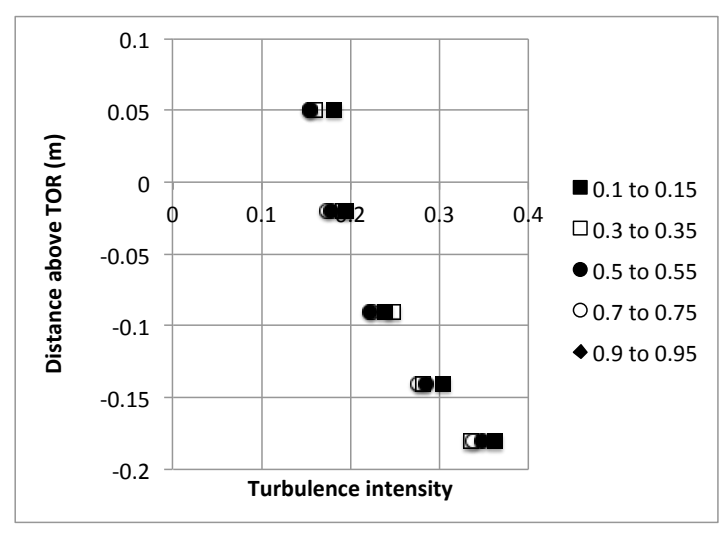

b) Turbulence intensity profiles for different positions along the train

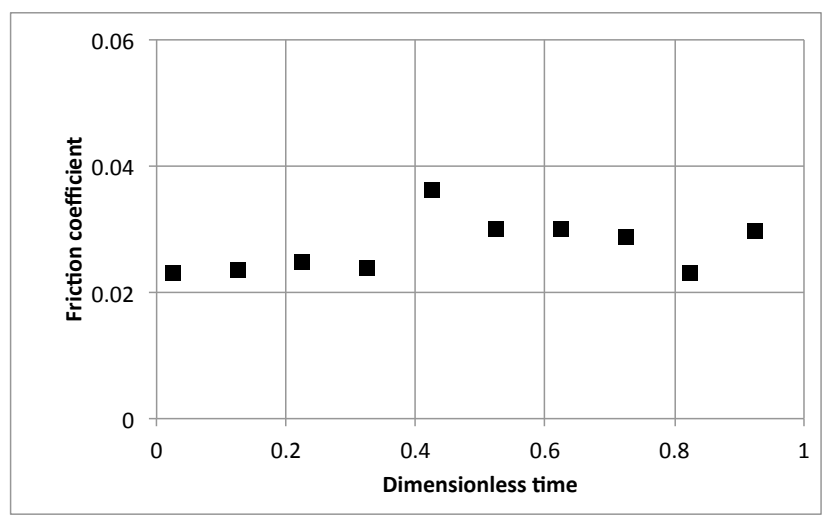

d) Friction coefficient development $C \tau$

Figure 13. Velocity analysis 


\subsection{Correlation analysis}

The nature of the turbulence beneath the train can be further investigated by determining integral length scales (effectively the size of turbulence gusts) from the autocorrelations of velocity. The autocorrelation function is defined as

$R_{u u}=\frac{u(T) u(T+\epsilon)}{\overline{u(T)^{2}}}$

where $u(T)$ is the velocity at dimensionless time $T$ and $\varepsilon$ is a time lag. Figure 14 shows these functions for the measured velocities at all heights, for a range of dimensionless time $T$ of 0.25 to 0.3 (over which period the velocities show little change). All the autocorrelations drop very rapidly to zero over a range of $\varepsilon$ of 0.005 , and then oscillate to varying degrees about zero. The dimensionless integral time scale can be calculated as the integral of the autocorrelation function from a lag of zero to the first zero crossing. These values are given in Table 3 below; they are of the order of 0.001 to 0.002 , which in dimensional terms corresponds to integral length scales of $0.4 \mathrm{~m}$ to $0.8 \mathrm{~m}$. Note that these values are close to the spatial limit of resolution of the velocity measurements. Thus the turbulence energy beneath the train is mainly at very short scales. The higher lag time oscillations may indicate some long period oscillations of the flow with periods of 0.02 (length scales of around $8 \mathrm{~m}$ ), but the correlations are small hence any conclusions in this regard must be very tentative.

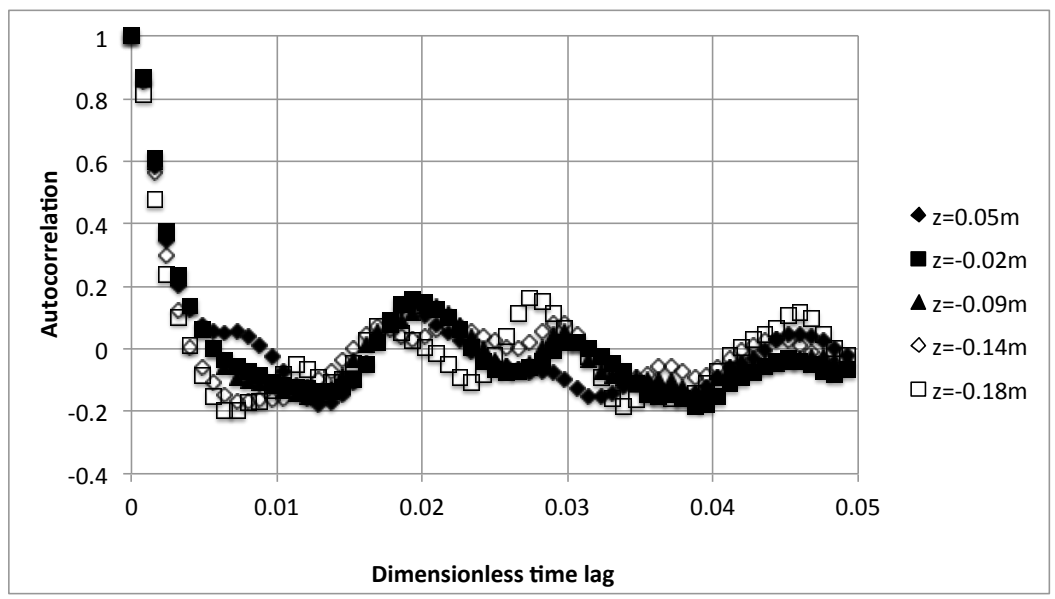

Figure 4 Velocity correlations

Table 3 Calculated dimensionless integral time scales

\begin{tabular}{|c|c|c|c|c|c|}
\hline$z(\mathrm{~m})$ & 0.05 & -0.02 & -0.09 & -0.14 & -0.18 \\
\hline $\begin{array}{c}\text { Integral } \\
\text { time scale }\end{array}$ & 0.0024 & 0.0023 & 0.0023 & 0.0015 & 0.0012 \\
\hline
\end{tabular}




\subsection{Bogie velocity analysis}

Figure 15 show expanded versions of the velocity profile ensemble plots at the track centre line; the positions of the bogie centres are also indicated. The different types of bogie outlined in Section 2 are clearly identifiable. The double bogie at the end of the front coach seems to be associated with an increase in flow speeds, although this may simply be due to the boundary layer development along the train. The double bogie at the rear is followed by a decrease in flow speeds, although again this seems to be associated as much with the end of the train as with the bogie itself. The articulation bogies along the train do not seem to affect the measured velocities to any extent. However the major effect on the velocity field occurs at the central bogie pair, with a step change in velocity occurring just behind it. It is shown below that this has a major effect on the possibility of ballast flight initiation.

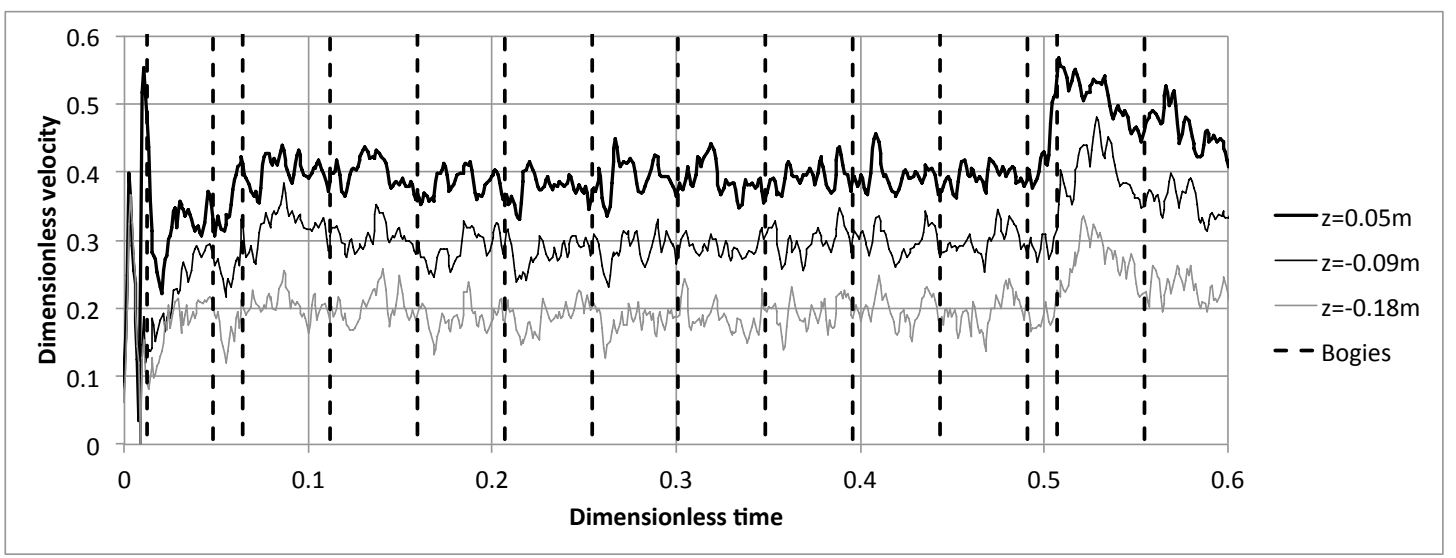

a) $0<T<0.6$ (First trainset)

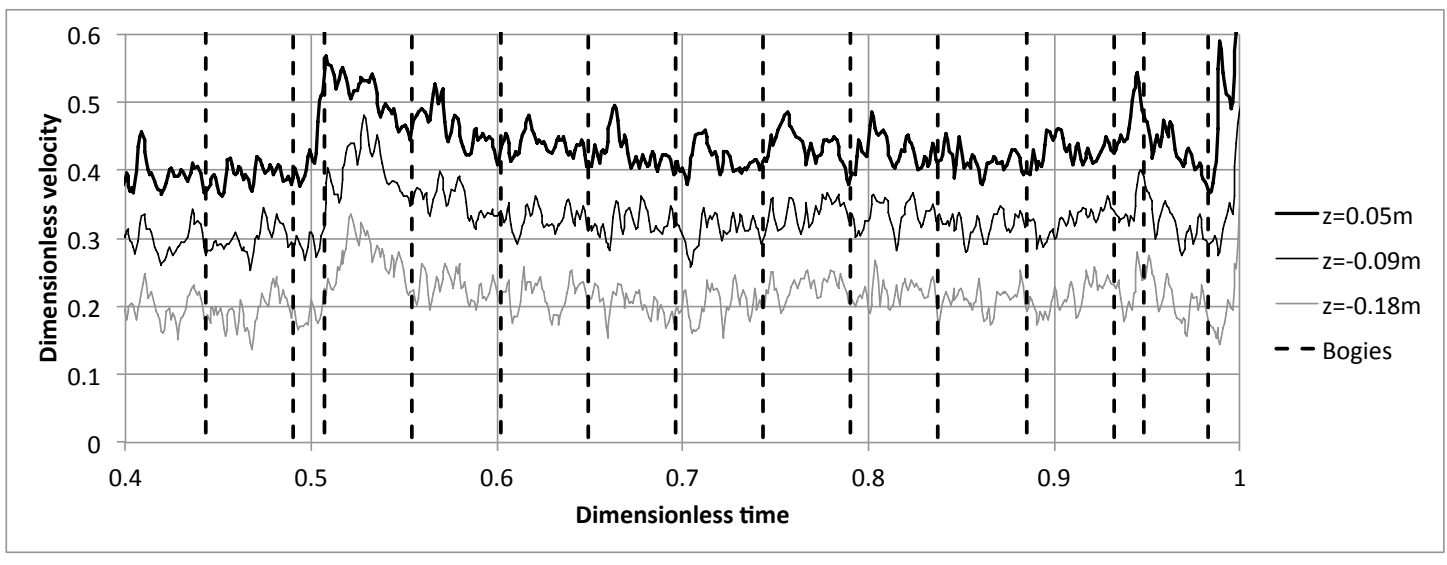

b) $0.4<T<1$ (second trainset)

Figure 15. Expanded velocity ensembles showing bogie positions 


\subsection{Ballast force analysis}

As explained in Section 1, the relative importance of aerodynamic forces on the ballast and the forces due to track displacement and acceleration as the train passes has not yet been fully established. The data described here, with simultaneous measurements of aerodynamic and mechanical parameters, enables some calculations to be made of the relative magnitudes of the different forces on the ballast, and how these affect its stability. The forces acting on a ballast grain during the passage of a train are

- the weight of the ballast particle;

- the aerodynamic pressure force acting in a vertical direction;

- the reaction between the ballast bed and the particle acting in a vertical direction;

- the aerodynamic shear force acting in the horizontal direction;

- the friction force acting in a horizontal direction such as to resist motion.

First consider the vertical forces. The weight is of course simply given by $M g$, where $M$ is the mass of the ballast particle and acts vertically downwards. The pressure force is given by

$P=-0.5 \rho V_{\text {train }}{ }^{2} A C_{p}$

where $A$ is the horizontal surface area of the particle. If the pressure force just acts on the upper surface of the particle, then $C_{p}$ will be given by the data shown in figures 9 and 10 . Note that the minus sign indicates that positive pressures will act downwards. However it is likely there will be some leakage of pressure through the ballast bed, and the effective pressure coefficient will be lower than this. To obtain the reaction force $R$ we write the equation of motion in a vertical direction as

$M f=R+P-M g$

where $f$ is the measured ballast acceleration and $M f$ is the effective inertial force. Thus

$R=M f+M g-P$

Now consider the horizontal forces. Shear forces at the ballast surface have been characterised above by a friction coefficient

$$
C_{\tau}=2\left(\frac{u_{\tau}}{V_{\text {train }}}\right)^{2}=\frac{\tau}{0.5 \rho V_{\text {train }^{2}}}
$$

This is essentially a mean parameter, defined over specific spatial distances along the train. It can be related to the average drag force on a grain of ballast through the expression

$C_{\tau} d^{2}\left(0.5 \rho V_{\text {train }}{ }^{2}\right)=C_{D} A\left(0.5 \rho \bar{u}^{2}\right)$

where $d$ is the ballast dimension, $C_{D} A$ is the drag coefficient multiplied by the exposed area of the ballast and $\bar{u}$ is the mean velocity close to the bed, averaged over the length of the train. The instantaneous shear force can then be calculated by the quasi-steady assumption

$S=C_{D} A\left(0.5 \rho u^{2}\right)=C_{\tau} d^{2} V_{\text {train }}{ }^{2}\left(\frac{V_{\text {train }}}{\bar{u}}\right)^{2}\left(\frac{u}{V_{\text {train }}}\right)^{2}$

where $u$ is the instantaneous velocity near the bed. This assumes that the bed shear stress is effectively the sum of the drag on all the individual ballast particles, and is effectively 
caused by the bed roughness. As such it effectively integrates all the form drag of the particles. Note that there area number of significant assumptions that underpin this determination of shear - the determination of the shear stress from the boundary layer, the averaging over the length of the train, and the use of the quasi-steady assumption. Finally the friction force acting to resist motion in a horizontal direction is given by

$F=\mu R$

where $\mu$ is a friction coefficient. Strictly speaking the last definition is only correct when if $S>\mu R$ i.e. the particle is moving. For lower values of shear the friction is balanced by the shear force.

Figure 16 shows, for Run 7, plots of the time variation of the pressure force $P$, the inertial force $M f$, the reaction force $R$, the shear force $S$ and the net horizontal force $S-F$, based on the above analysis for a square cube of side $d=0.04 \mathrm{~m}$, assuming $C_{\tau}=0.03, \mu=0.6$, and $V_{\text {train }}=83 \mathrm{~m} / \mathrm{s}$ as in the experiments. $\mathrm{S}$ will be negative when the particle is not moving. The weight of the particle is $0.794 \mathrm{~N}$. The data is taken directly from the earlier figures i.e. for a sampling time of $1 / 180$ s. Necessary, but not sufficient conditions for ballast movement are either $R<0$ (when the particle will lift) or $S-F>0$ (when the particle will slide or roll). At this point the many assumptions leading to these plots needs to be emphasised, but they do allow a comparison to be made between the magnitudes of the different forces acting on the particle. Perhaps the most important point is that all the forces are roughly of the same order of magnitude i.e. of the order of one Newton and none can be ignored $a$ priori. The pressure force unsurprisingly has peaks at the front and end of the train, and the inertial force is effectively the ballast acceleration multiplied by mass. The reaction force is a combination of these two forces and the weight. For the case being considered, this falls to zero at the front and end of the train and at a small number of bogies between, and thus the particle loses contact with the bed. The shear force reflects the velocity close to the bed of course, and the friction force (not shown) is simply the reaction multiplied by the friction factor. The overall horizontal force thus reflects the pressure and velocity fields, as well as the ballast acceleration. It rises above zero on a number of occasions, mainly associated with the passage of the bogies and thus the particle will be able to be move.

In view of the artificial nature of the assumptions, it would be unwise to generalise further concerning the nature of the initiation of ballast movement, but it is clear it is a complex process with a variety of different physical mechanisms playing a role. One point is clear however. The ballast accelerations described here were obtained from a well performing section of track. For a poorly performing section of track, with voids beneath the sleepers, the accelerations have been measured to be very much higher. Thus any ballast particles on the surface of such sleepers would experience these accelerations and the reaction force could be expected to dip below zero very much more frequently than in the hypothetical case considered here. 


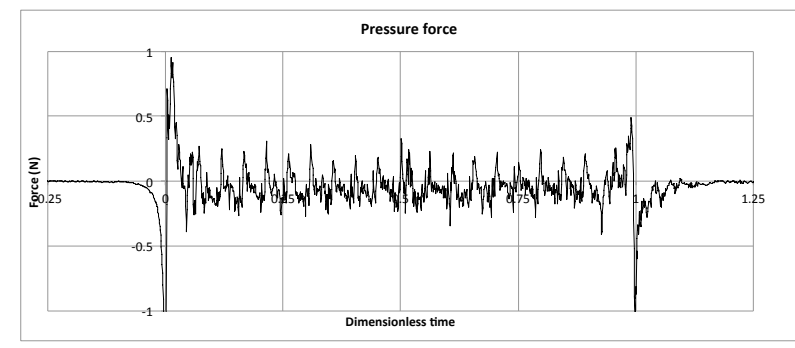

(a) Pressure force $P$

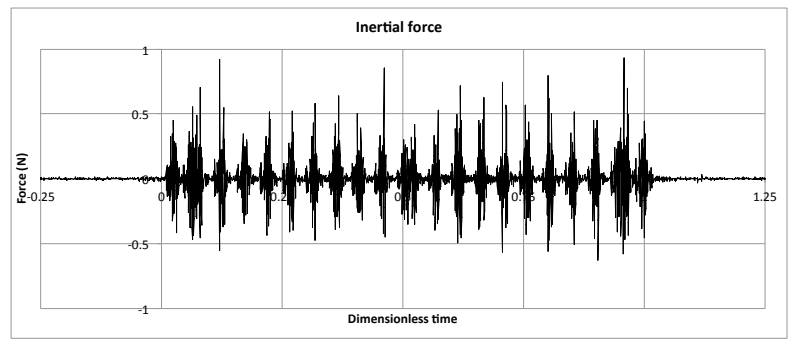

(b) Inertial force $M f$

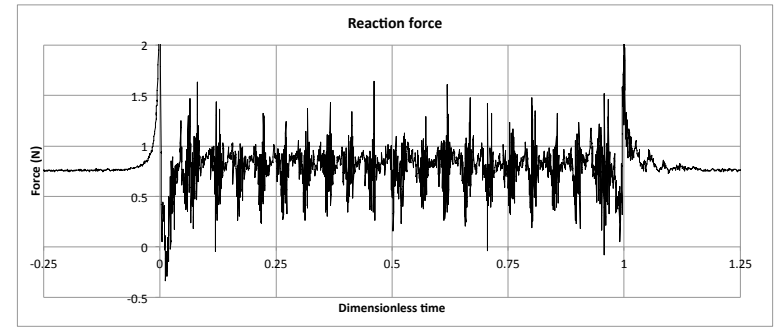

(c) Vertical reaction force $R$

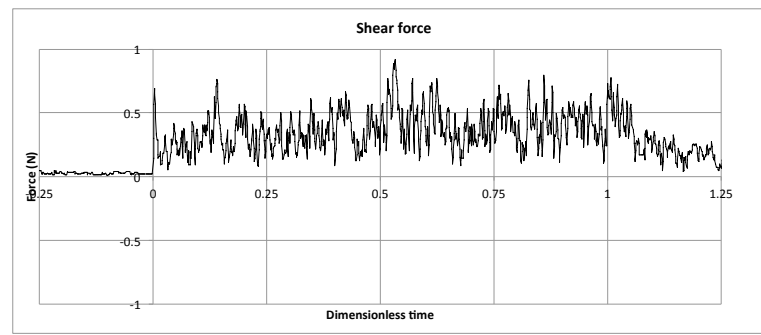

(d) Shear force $S$

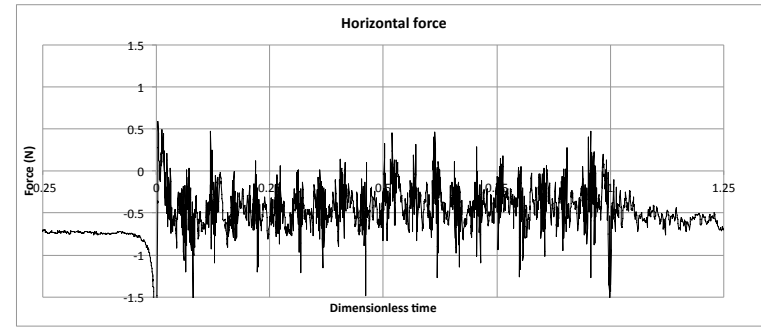

(e) Net horizontal force $S$ - $F$

Figure 16 Forces on hypothetical cubic ballast particle

25 


\section{Conclusions}

From the material presented in this paper, the following conclusions can be drawn.

- Measurements of track displacement and ballast acceleration were very consistent across all train runs, showing little variation.

- Aerodynamic measurements, particularly of velocity, indicated a much greater degree of variability (as would be expected), and ensemble averaging was needed to reveal fully their spatial and temporal variations.

- Ballast grain vertical accelerations were largely driven by track displacements as the train passed, and were not correlated with aerodynamic effects.

- Assessment of the magnitudes of the external forces acting on ballast grains showed that the mechanical forces associated with track displacement and the aerodynamic forces were of similar order of magnitude on well performing track.

- The vertical reaction force and the overall horizontal force are complex combinations of a range of physical phenomena.

- For poorly maintained track with greater vertical accelerations the results suggest that the possibility of ballast flight may be greatly increased.

\section{Acknowledgments}

The work in this paper was funded by EPSRC project EP/K037676/1. The authors would like to thank Network Rail High Speed for their assistance with the field monitoring and Eurostar International Ltd for their cooperation throughout the project.

\section{References}

Bowness D, Lock A C, Powrie W, Priest J A and Richards D J (2007) Monitoring the dynamic displacements of railway track. Proceedings of the Institution of Mechanical Engineers, Part F: Journal of Rail and Rapid Transit 221(1):13-22

Campbell Scientific. 2014. http://www.campbellsci.com/cr9000x. [Accessed 20 April 2017]

CEN (2013) Railway Applications - Aerodynamics Part 4 Requirements and test procedures for aerodynamics on open track, EN14067-4:2013

Deeg P, Jonsson M, Kaltenbach H-J, Schober M, Weise M (2008) Cross-comparison of measurement techniques for the determination of train induced aerodynamic loads on the trackbed, Bluff Body Aerodynamics and its Application, BBAA6 Milano, 16 pages

Garcia J, Crespo A, Berasarte A, Goikoetxea J (2011) Study of the flow between the train underbody and the ballast track, Journal of Wind Engineering and Industrial Aerodynamics 99, 1089-1098

Ido A, Saitou S, Nakade K, Ikura S (2008) Study on under-floor flow to reduce ballast flying phenomena, World Congress on Rail Research, WCRR8 Seoul, 12 pages 
Ido A, Yoshioka S (2009) Development of a model running facility for study of under floor flow, Speed up, Safety and Service Technology for Railway and Magleve Systems, STECH 2009 Niigata 6 pages

Ido A, Yamazaki N, Kurita T, Yoshioka S (2013) Study on under-floor flow of railway vehicle using on-track tests with a Laser Doppler Velocimetry and moving model tests with comb stagnation pressure tubes, World Congress on Rail Research, WCRR10 Sydney, 6 pages

Irwin H P A H, Cooper K R, Girad R (1979) Correction of distortion effects caused by tubing systems in measurements of fluctuating pressures, Journal of Industrial Aerodynamics 5, 93-107

Jing G Q, Zhou Y D, Lin J, Zhang J (2012) Ballast flying mechanism and sensitivity factors analysis, International Journal on Smart Sensing and Intelligent systems 5, 4, 928-939 Montreal, 10 pages

Jonnson M, Wagner C, Loose S (2012) Particle image velocimetry of the underfloor flow for generic high-speed train models in a water towing tank, Proceedings of the Institution of Mechanical Engineers. Part F Journal of Rail and Rapid Transit, 228, 2, $194 \quad$-209

Jonsson M, Wagner C, Loose S (2013) Underfloor flow measurements of a 1:50 generic highspeed train-set by means of high-speed PIV in a water towing tank, World Congress on Rail Research, WCRR10 Sydney, 6 pages

Kaltenbach H-J, Portillo I, Schober M (2008) A generic train-underfloor experiment for CFD validation, Bluff Body Aerodynamics and its Application, BBAA6 Milano, 16 pages

Kaltenbach H-J (2008) DeuFraKo Project - Aerodynamics in Open Air (AOA) WP 1 Underfloor Aerodynamics Summary Report

Kaltenbach H-J, Gautier P-E, Agirre G, Orellano A, Schroeder-Bodenstein K, Testa M, Tielkes Th (2008) Assessment of the aerodynamic loads on the trackbed causing ballast projection: results from the DEUFRAKO project Aerodynamics in Open Air (AOA), Proceedings of the World Congress on Rail Research, Seoul, South Korea, Paper number S2.3.4.1

Kwon H-B, Park C-S (2006) An experimetal study on the relationship between ballast flying phenomenon and strong wind under high speed train, World Congress on Rail Research, WCRR7

Lamas-Lopez, F., Alves-Fernandes, V., Cui, Y. J., Costa D'aguiar, S., Calon, N., Canou, J., Dupla, J. C., Tang, A. M. \& Robinet, A. 2014. Assessment of the double integration method using accelerometers data for conventional railway platforms. In Proc: The Second International Conference on Railway Technology : Research, Development and Maintenance, 8-11 April 2014, Ajaccio, France.

Le Pen, L., Watson, G., Powrie, W., Yeo, G., Weston, P. \& Roberts, C. 2014. The behaviour of railway level crossings: Insights through field monitoring. Transportation Geotechnics, 1, 201-213.

Le Pen, L., Milne, D., Thompson, D. \& Powrie, W. 2016. Evaluating railway track support stiffness from trackside measurements in the absence of wheel load data. Canadian Geotechnical Journal, 53, 1156-1166. 
Luo Y, Yin H, Hua C (1996) Thedynamic response of railway ballast to the action of trains moving at different speed, Proceedings of the Institution of Mechanical Engineers, Journal of Rail and RapidTransit 210, 95-101

Milne D. Le Pen L, Thompson D J and Powrie W (2016a) Measurement of ballast grain acceleration at track level. The Journal of the Permanent Way Institution 134(4).

Milne D, Le Pen L, Watson G, Thompson D, Powrie W, Hayward M and Morley S (2016b) Proving MEMS Technologies for Smarter Railway Infrastructure. Procedia Engineering 143:1077-1084.

Moran P and R. Hoxey (1979). A probe for sensing static pressure in two-dimensional flow. Journal of Physics E: Scientific Instruments 12 (8), 752.

Premoli A, Rocchi D, Schito P, Somaschini C, Tomasini G (2015) Ballast flight under highspeed trains: Wind tunnel full-scale experimental tests, Journal of Wind Engineering and Industrial Aerodynamics 145, 351-361

Quinn A D, Hayward M, Baker C J, Schmid F, Priest J A, Powrie W (2010) A full-scale field monitoring and modelling study of ballast flight under high-speed trains, Proceedings of the Institution of Mechanical Engineers, Part F: Journal of Rail and Rapid Transit 224, 2 6174, 10.1243/09544097JRRT294

Sanz-Andres A, Navarro-Medina F (2010) The initiation of rotational motion of a lying object caused by wind gusts, Journal of Wind Engineering and Industrial Aerodynamics 98, 772-783

Saussine G, Masson E, Jaques T-J, Paradot N, Allain E, Josse F (2009) Railway Ballast flying phenomena - from numerical simulation towards risk assessment, EUROMECH Colloquim 509, Vehicle Aerodynamics, External aerodynamics of railway vehicles, trucks, buses and cars, Berlin, Germany

Saussine G, Allain E, Vaillant A, Ribourg M, Néel O (2013) High speed in extreme conditions: ballast projection phenomenon, Proceedings of the International Workshop on Train Aerodynamics, Birmingham, UK

Shinojima K (1984). Study on the Phenomena of Snow Adhering to and Dropping from Shinkansen Train, and the Countermeasures. Quarterly Reports 25, 2, 41 - 44

Sima M, Gurr A, Orellano A (2008) Validation of CFD for the flow under a train with 1:7 scale wind tunnel measurements, Bluff Body Aerodynamics and its Application, BBAA6 Milano, 16 pages

Sima M, Grappein E, Weise M, Paradot N, Hieke M, Baker C, Licciardello R, Couturier M (2011) "Presentation of the EU FP7 AeroTRAIN project and first results", World Congress of Rail Research, Lille

TSI (2014) Technical specification for interoperability relating to the 'rolling stock locomotives and passenger rolling stock' subsystem of the rail system in the European Union Locomotives and passenger rolling stock - LOC \& PAS TSI, 1302/2014/EU

Weise M, Sima M (2013) Towards a Standard Test Procedure for Aerodynamic Loads on Railway Tracks, Train Aerodynamics Workshop, Birmingham, 4 pages 